\title{
Review Article \\ The Discovery of Novel Experimental Therapies for Inflammatory Arthritis
}

\author{
Charles J. Malemud \\ Division of Rheumatic Diseases, Department of Medicine, University Hospitals Case Medical Center, \\ Case Western Reserve University School of Medicine, Cleveland, OH 44106, USA \\ Correspondence should be addressed to Charles J. Malemud, cjm4@po.cwru.edu
}

Received 25 September 2009; Accepted 21 December 2009

Recommended by Fulvio D’Acquisto

Conventional and biologic disease-modifying antirheumatic drugs have revolutionized the medical therapy of inflammatory arthritis. However, it remains unclear as to what can be done to treat immune-mediated chronic inflammation after patients become refractory to these therapies or develop serious side-effects and/or infections forcing drug withdrawal. Because of these concerns it is imperative that novel targets be continuously identified and experimental strategies designed to test potential arthritis interventions in vitro, but more importantly, in well-validated animal models of inflammatory arthritis. Over the past few years, sphingosine-1-phosphate, interleukin-7 receptor, spleen tyrosine kinase, extracellular signal-regulated kinase, mitogenactivated protein kinase 5/p38 kinase regulated/activated protein kinase, micro-RNAs, tumor necrosis factor-related apoptosis inducing ligand and the polyubiquitin-proteasome pathway were identified as promising novel targets for potential antiarthritis drug development. Indeed several experimental compounds alter the biological activity of these targets and have shown clinical efficacy in animal models of arthritis. A few of them have even entered the first phase of human clinical trials.

Copyright (C) 2009 Charles J. Malemud. This is an open access article distributed under the Creative Commons Attribution License, which permits unrestricted use, distribution, and reproduction in any medium, provided the original work is properly cited.

\section{Introduction}

The therapy of various types of inflammatory arthritis, including, adult rheumatoid arthritis (RA), juvenile idio-pathic arthritis (JIA), psoriatic arthritis and ankylosing spondyloarthopathy that were previously treated with glucocorticoids, nonsteroidal antiinflammatory drugs, gold and bed rest was revolutionized by the introduction of the conventional disease-modifying antirheumatic drugs (DMARDs), hydroxychloroquine, sulfasalazine, leflunomide, azathioprine, cyclosporine, minocycline and methotrexate monotherapy or several combined conventional and biologic DMARD therapies into the standard of medical care [1-3]. The advent of the use of biologic DMARDs, including the 5 forms of anti-TNF- $\alpha$-receptor blocking molecules, infliximab, adalimumab, certolizumab pegol, golimumab and etanercept [4-7], interleukin-1receptor antagonist (IRAP) [8, 9], results from recent clinical trials with canakinumab, a fully human monoclonal antibody that neutralizes the bioactivity of human IL- $1 \beta$ [10], abatacept, a selective modulator and inhibitor of the
T-cell costimulatory molecule CTLA-4 [11-13] and the monoclonal antibody, rituximab which deletes a subset of immature and/or memory B-cells expressing the CD20 cell surface protein marker [14-16] has added to the armamentarium of useful drugs to treat patients with inflammatory arthritis. Additionally, the positive results obtained from recent clinical trials in adult RA and JIA patients indicated that additional novel agents such as the anti-IL-6 receptor (IL-6R) blocking monoclonal antibody, tocilizumab $[17,18]$, which has been approved for use in Europe, India and Japan are likely to be approved in the United States by the Federal Drug Administration in the not too distant future. Nevertheless, there is compelling evidence which indicates that patients with inflammatory forms of arthritis can become unresponsive or refractory to the currently available conventional DMARDs and/or biologic DMARDs and develop serious side-effects including neutropenia, auto-antibodies, antiidiotypic antibodies (even to some anti-TNF- $\alpha$ or anti-IL-6R monoclonal antibodies characterized as fully humanized) as well as reactivation and/or the onset of new bacterial infections especially at 
higher than recommended anti-TNF- $\alpha$ doses which may require withdrawing the drug [4, 19-24]. These findings in the biologic DMARD postmarketing surveillance period likely necessitates that new antirheumatic targets be continuously identified. Experimental agents that interact with these newly discovered targets must be thoroughly examined for their effects in vitro as well as in animal models of inflammatory arthritis prior to any consideration of their use in assessments of safety, efficacy and disease-modifying activity in patients with inflammatory arthritis.

A previously published compilation of review articles highlighted the recent advances in the identification of novel targets and cellular processes in RA, which included non-IL-1, non-TNF- $\alpha$ and non-IL-6 proinflammatory cytokines, chemokines, adhesion molecules, vascular endothelial growth factor and insulin-like growth factor1, matrix metalloproteinases (MMPs), complement and pro- and antiapoptosis molecules [25] as well as the Janus kinase/Signal Transducers and Activators of Transcription (JAK/STAT) pathway whereby the Jak3 inhibitor, CP690550 is the first small molecule inhibitor (SMI) to reach phase III clinical trials status [26], Mitogen-Activated Protein Kinase (MAPK) pathway $[27,28]$, and the IL-6/IL-6 receptor/gp130 complex $[29,30]$, all of which are applicable to additional basic and clinical studies wherein their future use in the medical intervention of adult and childhood RA and other inflammatory arthopathies may be further assessed.

This review will critically evaluate the extent to which several molecules, including, sphingosine-1-phosphate (S1P), IL-7-receptor (IL-7R), spleen tyrosine kinase (SyK), MEK/ERK 1/2, Mitogen-activated protein kinase 5/p38 kinase regulated/activated protein kinase (MK5/PRAK), microRNA (miRNA), tumor necrosis factor-related apoptosis-inducing ligand (TRAIL) and inhibitors of proteasome activity, appear to be promising novel experimental targets for future drug development for the treatment of inflammatory arthritis.

\section{Sphingosine-1-Phosphate (S1P)}

Sphingosine-1-phosphate (S1P) is a signaling sphingolipid and a bioactive lipid mediator [31]. Although once only recognized as regulator of angiogenesis, vascular homeostasis and permeability [31], the most recent evidence indicated that S1P was a critical regulator of T-cell and B-cell trafficking [32] and macrophage function [33]. Thus, the binding of S1P to its receptors, S1PR1/S1PR2 [34], triggers and is required for stimulating the movement of immune cells from the thymus and lymph nodes into lymphatic vessels from where they can travel through peripheral circulation to synovial joints. Additionally, it was shown that the secreted form of S1P also regulated cell survival and apoptosis by its capacity to bind to and activate 5 specific $G$ protein-coupled receptors, S1P1-S1P15 [35].

$\mathrm{S} 1 \mathrm{P}$ is produced by the activation (i.e., phosphorylation) of sphingosine (Sph) via its 2 isoforms of sphingosine kinase$1 / 2$ (SphK-1/2) resulting in the production of the prosurvival S1P molecule with decreasing levels of the proapoptotic
Sph molecule [35]. Thus, inhibiting the formation of S1P either by targeting SphK, or by inhibiting the binding of S1P to S1PR1/S1PR2 is likely to result in a reduced egress of activated T-cell and B-cell from lymphoid tissues and presumably fewer activated lymphocytes making their way into the synovium. These strategies may even be useful for also targeting apoptosis resistance which is a common hallmark of RA synovium [36, 37].

What is the current evidence that altering the activity of S1P would provide significant and beneficial effects by restricting some of the pathophysiologic events that contribute to inflammatory arthritis? Firstly, aberrant synovial cell proliferation is a signature event in RA [38]. Thus, it is likely that studying cell lines with an abnormal capacity for proliferation might be useful in dissecting out the role of S1P in regulating DNA synthesis. In that regard, several murine F9 embryonic carcinoma cell lines were produced with varying expressional levels of the S1P-degrading enzyme, S1P lyase (SPL) and/or SphK1 [39]. F9 cells overexpressing SphK1 exhibited elevated DNA synthesis, whereas other S1Paccumulating cells or SPL-null cells overexpressing SphK1 did not. These studies suggested that it was SPL, rather than $\mathrm{S} 1 \mathrm{P}$, that regulated mitogenesis in this cell line. Furthermore, genetic studies in mice expressing reduced levels of SPL showed decreased circulating lymphocytes as a result of alterations in lymphocyte trafficking and studies of lymphoid tissues following oral administration of 2-acetyl-4(5)-(1(R), 2(S), 3(R), 4-tetrahydroxybutyl)-imidazole, an experimental inhibitor of SPL, showed a clear relationship between reduced SPL activity, elevated S1P levels, and lower levels of circulating lymphocytes [40], thus supporting the targeting of S1P signaling as a potentially important antiinflammatory pathway [41].

Of note, on August 27, 2009, Lexicon Pharmaceuticals announced that an orally-administered SMI of SPL, 2-acetyl4(5)-(1(R), 2(S), 3(R), 4-tetrahydroxybutyl)-imidazole (i.e., LX2931), was being assessed in a Phase 2 multicentered randomized, double-blinded placebo-controlled clinical trial in the US and Eastern Europe on subjects with active RA who were also receiving methotrexate [42]. The ACR20 response to LX2931 will be the primary study endpoint. In the Phase la clinical trial conducted on normal volunteers, a dose-dependent decrease in absolute lymphocyte count and a maximal effect correlating with the plateau in systemic exposure at doses of 100 to $125 \mathrm{mg}$ of LX2931 was observed. An episode of acute abdominal pain which resolved within 24 hours was observed in 2 of 24 subjects in this single ascending-dose trial when subjects received doses of LX2931 above $175 \mathrm{mg}$, a dose which potentially represented (according to the manufacturer) a dose-limiting tolerability level.

Another line of evidence suggesting a role for S1P in RA stems from studies in which TNF- $\alpha$ induction of COX-2 activity and $\mathrm{PGE}_{2}$ synthesis was studied in L929 fibroblasts [43]. Of note, S1P induced COX-2 and $\mathrm{PGE}_{2}$ in a dosedependent (100-300 nM) manner. Small interfering RNAs (siRNA) directed against SphK decreased SphK1 protein and inhibited TNF- $\alpha$-induced SphK activity. Interestingly, siRNA directed against S1P or S1P phosphatase (SPP) also enhanced COX-2 and $\mathrm{PGE}_{2}$ production, whereas siRNA 
directed against SphK1 inhibited the effects of exogenous Sph and ceramide on the induction of $\mathrm{PGE}_{2}$ indicating that it was the intracellular metabolism of S1P that regulated COX-2 and $\mathrm{PGE}_{2}$ induction. However, the extent to which experimental strategies of this kind will produce similar results when employed in cultures of normal synovial fibroblasts or RA fibroblast-like synoviocytes (RA-FLS) has not been established. It is also noteworthy that silencing of SPP2 by siRNA also led to a marked reduction in TNF- $\alpha$ induced IL- $1 \beta$ and a partial reduction in IL- 8 in endothelial cells [44] suggesting that the targeting of SPP2 may also effectively limit the proinflammatory role of S1P.

\section{IL-7 Receptor}

Expression of the IL-7 receptor (IL-7R) gene (also known as CD127) plays a central role in thymocyte development [45], T-cell survival, B-cell maturation, T-cell-dendritic cell (DC) interactions $[46,47]$, as an inducer of lymphoid tissue development [48] as well as being useful for identifying Tregulatory $\left(T_{\text {reg }}\right)$ cells producing the FoxP3 phenotype [49]. To function normally, the IL-7R requires the presence of the IL-2 receptor gamma chain (IL-2R $\gamma$ ) which is the common $\gamma$-chain (Figure 1) that is shared by the receptors of various cytokines including IL-2, -4, -7-,-9 and -15, -21. In that context, IL-2R $\gamma$ has been reported to be critical for $\mathrm{V}(\mathrm{D}) \mathrm{J}$ recombination during lymphocyte development [50]. IL-7R was also found to important in regulating the accessibility of the T-cell receptor (TCR) $\gamma$-locus (TCR- $\gamma$ ) by STAT5 and histone acetylase [51]. Thus, overexpression of IL-7R $\alpha$ is likely to be highly relevant to the pathogenesis and even to the progression of inflammatory arthritis.

For example, it was shown that murine T-cell and Bcell development was dependent on IL-7R $\alpha$, in that forced expression of the antiapoptosis gene $\mathrm{Bcl}-2$ in murine $\mathrm{T}$ cells from IL-7R $\alpha$ deficient mice resulted in restoration of thymic positive selection and normal T-cell numbers and function [52]. Interestingly, a deficiency in the proapoptosis gene, Bax, also partially corrected IL-7R $\alpha$ deficiency and the $\mathrm{BH} 3$-domain containing apoptosis proteins Bad and Bim were implicated as contributing to the apoptosis pathway suppressed by IL-7/IL-7R [53]. Additionally, in contrast to IL-7R null mice, Flt3 null mice crossed with IL-7R null mice failed to produce mature B-cells or for that matter, B-cell precursors during fetal development [54]. Taken together, these results indicated that IL-7R $\alpha$ was required for normal T-cell and B-cell development. Thus, defective or overexpressed IL-7/IL-7R $\alpha$ signaling could be critical in the regulation of other receptor-mediated events that regulate apoptosis as well as immune-mediated events that contribute to inflammatory arthritis.

Several criteria needed to be met in order for IL-7R to be further considered as a promising target for experimental intervention in inflammatory arthritis. First and foremost would be evidence for elevated levels of IL-7 in the synovial fluid of joints with inflammatory arthritis. A recent review of the literature by Churchman and Ponchel [55] indicated that this indeed was the case. However, one of the first indications that IL-7 was likely to play a critical role in experimental inflammatory arthritis also stemmed from the earlier studies by Sawa et al. [56] who showed that mice homozygous for the F759 mutation in the gp130/IL-6R subunit showed elevated Stat3 activation and a rheumatoid-like arthritic joint disease. Furthermore, the gp130 mutation resulted in elevated levels of IL-7. In turn, conditional knockout of Stat3 in nonlymphoid cells showed that the increased levels of IL-7 in these mice were Stat3-dependent. Anti-IL-7 antibody not only inhibited $\mathrm{CD} 4^{+} \mathrm{T}$-cell proliferation (which was a requirement for the development of arthritis) but anti-IL-7 antibody administration also ameliorated arthritis severity. Thus, arthritis produced in these mice by the F759 mutation in gp130 required not only homeostatic $\mathrm{CD}^{+} \mathrm{T}$ cell expansion but upregulation of IL-7 gene expression in nonhemopoietic cells as well.

Turning to studies in human RA, Kim et al. [57] showed that elevated levels of IL- $1 \beta$ and TNF- $\alpha$ in RA synovial fluid typically increased stromal cell production of IL-7 in vitro. In turn, IL-7 was also shown to upregulate production of TNF$\alpha$ in monocytes. Of note, IL-7 was shown to be an important inducer of osteoclastogenic cytokines in T-cells by RANKL, the latter a strong promoter of bone destruction in RA. Most importantly, this event was apparently independent of TNF- $\alpha$ [58], suggesting that anti-TNF- $\alpha$ therapies would be unlikely to completely abrogate IL-7-mediated cellular events in RA. However, van Roon et al. [59] showed in vivo that TNF- $\alpha \mathrm{R}$ blockade did block IL-7 production in those RA patients that responded to anti-TNF- $\alpha$ therapy, but high IL-7 levels persisted in anti-TNF- $\alpha$ nonresponders. More recently, Hartgring et al. [60] also found significantly higher levels of IL7R $\alpha$ in the synovial fluid from RA and undifferentiated arthritis patients which strongly correlated with elevated levels of IL-7 and increased numbers of the $\mathrm{CD}^{+}$T-cell subset. Interestingly, a large number of B-cells and macrophages also expressed IL-7R $\alpha$ although this was less significant than was found for T-cells. Additionally, there was a strong correlation between IL-7R $\alpha$-expressing T-cells that also failed to express FoxP3 which showed marked proliferation in vitro compared to IL-7R $\alpha$-expressing Tcells that expressed FoxP3. Experimental ex vivo studies on monocytes collected from RA patients when treated with recombinant human soluble IL-7R $\alpha$ in vitro inhibited IL-7-induced T-cell proliferation and interferon- $\gamma$ (IFN$\gamma$ ) production, suggesting that IL-7R $\alpha$ blockade might of potential importance as an alternative strategy to TNF- $\alpha$ blockade for limiting IL-7-induced RA immunopathology. This point was also stressed by Vudattu et al. [61] for treating patients with autoimmune diseases associated with central nervous system inflammation.

\section{Spleen Tyrosine Kinase}

Spleen tyrosine kinase (SyK) (Figure 2 ) and $\zeta$-chain associated protein-70 (ZAP-70) are nonreceptor kinases that are primarily expressed in hemopoietic cells, including cells of the spleen, mast cells, neutrophils and macrophages [62]. Syk and ZAP-70 are also involved in T-cell and B-cell receptor 


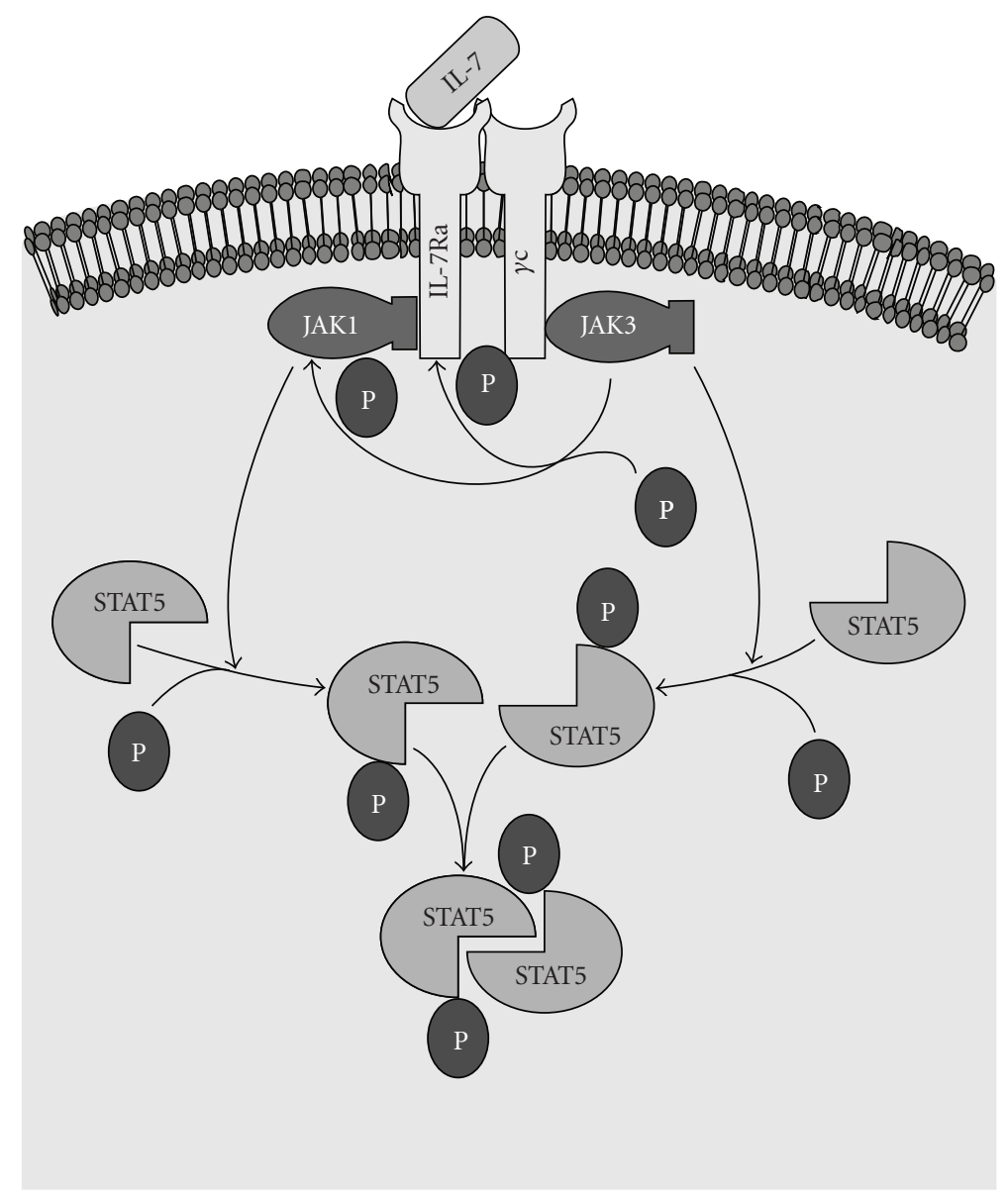

FIgure 1: The IL-7/IL-7R Pathway. The IL-7R is composed of a $\gamma \mathrm{C}$ and $\mathrm{R} \alpha$ polypeptide. The $\mathrm{R} \alpha$ component is unique to the IL-7R, whereas $\gamma \mathrm{C}$ is common to several cytokine-mediated pathways, including IL-2, IL-4, IL-9, IL-15 and IL-21. The binding of IL-7 to R $\alpha$ results in the dimerization of $\gamma \mathrm{C}$ and $\mathrm{R} \alpha$. JAK3 is associated with $\gamma \mathrm{C}$. After dimerization of $\gamma \mathrm{C}$ with $\mathrm{R} \alpha$, JAK3 can phosphorylate R $\alpha$ and/or JAK1. Activation of JAK3 results in phosphorylation of STAT5. Phosphorylation of STAT5 is required for STAT5 to act as a transcription factor (reviewed in [26]).

signaling potentially making Syk and ZAP-70 enzyme targets for the treatment of autoimmune diseases [63]. Of note, since Cbl ubiquitin ligase was previously shown to be a negative regulator of Syk [64], various experimental attempts have been made to limit SyK activation through targeting of the polyubquitination-proteasome pathway $[65,66]$.

Because of its apparent critical role in regulating T-cell and $\mathrm{B}$-cell expansion and the proliferation of cells containing the $\mathrm{F} \gamma$-activating receptor as well as mediating immunoreceptor signaling in inflammatory cells and immune complexmediated signal transduction, SyK must be considered a promising target for designing interventional drugs for the treatment of immune-mediated inflammatory arthritis. At the experimental level, Pine et al. [68] showed that R788 a prodrug of the active novel SyK small molecule inhibitor R406 suppressed the severity of arthritis, bone erosions, pannus development and synovitis in murine collageninduced arthritis (CIA). The reduced expression of SyK in the R788-treated mice correlated with an amelioration of clinical arthritis, a reduction in proinflammatory chemokines and cytokines, including the CXCR2 ligand KC-GRO- $\alpha$, macrophage chemoattractant protein-1 (MCP-1), IL-1, and IL-6, as well as inducing suppression of cartilage oligomeric matrix protein release, the latter protein a sensitive in vitro biomarker for articular cartilage extracellular matrix degradation.

Because of the apparent successful preclinical response to R788 in the well-validated CIA animal model of RA, a Phase II clinical trial involving, fostamatinib (R406), was conducted. Fostamatinib effectively improved clinical RA response rates within a 3 month treatment period with gastrointestinal side-effects, principally diarrhea, and neutropenia, which was related to the fostamatinib dose employed, the most commonly reported adverse events [69]. In addition to improving clinical outcomes measurements as determined by the American College of Rheumatology (ACR) criteria as early as 1 week after oral administration, R406 also reduced the level of serum IL-6 and MMP-3 (stromelysin-1) in the groups receiving $100 \mathrm{mg}$ and $150 \mathrm{mg}$ of R406 twice daily [70]. However, it remains to be determined as to the extent that R406 can be continuously employed in the treatment of chronic RA, the extent to which reduced levels of SyK 


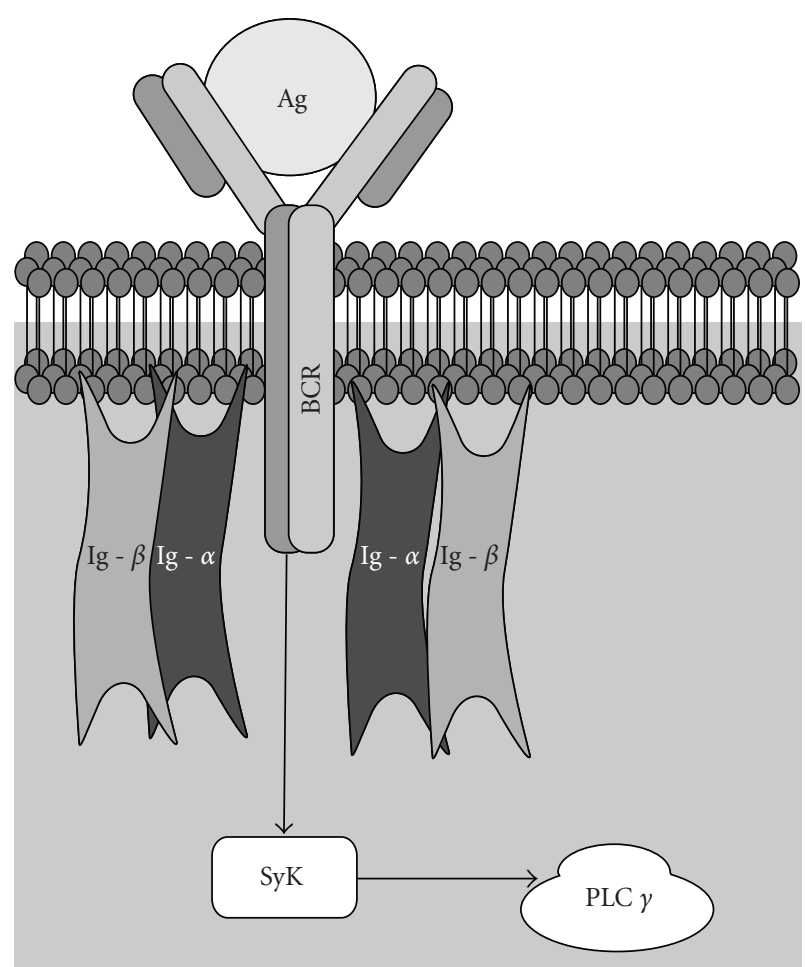

Figure 2: The Role of Syk in Antigen-Mediated Activation of the B-cell Receptor. The B-cell receptor (BCR) is composed of a ligand binding moiety that interacts with antigen $(\mathrm{Ag})$ and $\mathrm{a}$ signaling moiety in the form of the heterodimer, Ig- $\alpha / \operatorname{Ig}-\beta$ complex, (also known as CD79) which is held together by disulfide bridges. Each component of the Ig- $\alpha / \operatorname{Ig}-\beta$ heterodimer complex spans the plasma membrane and also possesses a cytoplasmic tail component containing the immunoreceptor tyrosine-based activation motif (ITAM). In this example, the binding of Ag to BCR triggers phosphorylation of Syk. Activation of Syk regulates phospholipase $\mathrm{C} \gamma$ (PLC $\gamma)$ activity. PLC $\gamma 2$ was recently shown to be required for the formation, maintenance and survival of memory B cells within germinal centers [67].

are maintained by administration of R406 and whether R406 therapy will show a sustained improvement in arthritis symptoms compared to that obtained with conventional or biologic DMARDs.

\section{MEK/ERK 1/2}

ERK $1 / 2$ belongs to the SAP/MAPK family of protein kinases. ERK $1 / 2$ must be activated before it can act as a fully activated protein kinase and as such the activation of an MAPK such as ERK $1 / 2$ is generally carried out by one of at least 7 upstream MKK proteins [71]. Moreover, MKK activity is also regulated by further upstream MKKK and MKKKK activity that are either tyrosine or serine-binding proteins which may also require low molecular weight GTP-binding proteins for MKKK activation. Much of the accumulated evidence has indicated that the MKK-MAPK activated protein kinase complex is further organized by additional scaffolding proteins that provide the structural requirements for specific MKKK activation selectivity for the action of GTPases, additional protein kinases and receptors [72].

MEK is the key regulatory protein kinase activation in the Ras/Raf/MEK/ERK pathway (Figure 3). In that regard, MEK is critical for the upregulation of several proinflammatory cytokines, including, TNF- $\alpha$, IL- $1 \beta$ and IL-6 [73]. Additionally, in the context of inflammatory arthritis, recent studies using the novel MEK SMI AZD6244 showed that AZD6244 inhibited osteoclastic differentiation, function and cytokine production in dentine disc cultures [74] whereas a previous study showed that 2 MEK SMIs, U0126 and PD98059, blocked osteoclast development from the RAW264.7 preosteoclastic cell line [75]. These results suggested that MEK blockade could be useful for attenuating proinflammatory cytokine synthesis as well as for suppressing osteoclastmediated bone erosions in inflammatory arthritis. However, the "cross-talk" that is known to occur between the JAK/STAT and MEK/ERK pathway [28, 76] likely also creates an added layer of complexity for regulating osteoclast function in inflammatory arthritis since the JAK/STAT pathway has also been considered as a suitable target pathway for the suppression of inflammatory disorders [26]. In that regard, Kwak et al. [77] showed that AG-490, an inhibitor of Jak2/Jak3 activity, actually induced osteoclast survival by activating both the MEK/ERK and PI3K/PTEN/Akt cell survival pathway. Thus, it is worthwhile considering the possibility that inhibition of osteoclast function using other novel strategies that target RANKL $[78,79]$ may also be required in this context.

Compelling evidence arising from malignant transformation studies in which MEK SMIs were employed in vitro has also implicated Raf/MEK/ERK [80] as a component of a "cross-talking" network with the PI3K/PTEN/Akt cell survival pathway [81]. The results of these studies suggested, however, that inhibition of MEK/ERK may have only limited therapeutic benefit for dampening synoviocyte proliferation and hyperplasia that is a hallmark of rheumatoid synovial pannus. Nevertheless, Thiel et al. [82] showed that the selective MEK SMI, PD184352 suppressed murine CIA paw edema and clinical arthritis scores while also reducing IL$1 \alpha$-induced activated ERK levels in human synovial fibroblasts as well as inhibiting proteoglycan loss from articular cartilage slices in vitro. Another experimental ERK inhibitor, FR180204, also suppressed murine CIA arthritis in which amelioration of clinical arthritis by FR180204 may also involve reduced antigen-specific activation of murine $\mathrm{T}$ cells [83]. However, in the first clinical trial of its kind in RA patients to employ a specific MEK SMI, ARRY-162, used in combination with a stable dose of methotrexate, none of the ARRY-162 treatment groups demonstrated a significant ACR20 response compared to placebo after 12 wks [84]. This result confirmed a previous European clinical trial with ARRY-162 which also failed to achieve a statistically significant outcome in clinical improvement. Thus, it remains to be determined if the "positive" results obtained in experimental inflammatory arthritis employing specific MEK/ERK SMIs can ever be translated into future use for the therapy of human RA. 


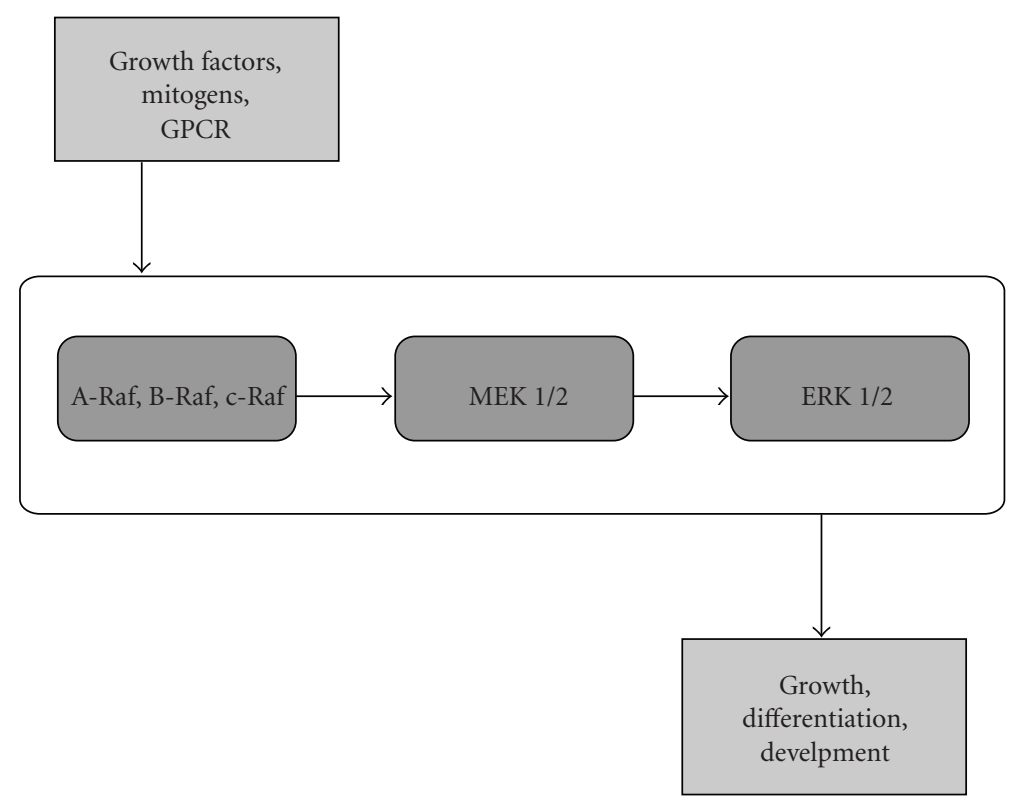

FIgure 3: Activation of MEK 1/2 and ERK 1/2 by MAP3K. The phosphorylation (i.e., activation) of A-Raf, B-Raf or c-RAF, by MAPKKK (i.e., MAP3K) results in MAP2K-mediated phosphorylation of MEK 1/2 and downstream activation of ERK 1/2 (reviewed in [27]).

\section{Mitogen-Activated Protein Kinase 5/p38 Kinase Regulated/Activated Protein Kinase}

Mitogen-activated protein kinase 5 (MK5) also known as p38 kinase regulated/activated protein kinase (PRAK) is a 471 amino acid protein with a $20 \%-30 \%$ sequence identity to the cyclic AMP responsive element binding protein, CREB-phosphorylating MAPK-regulated protein kinase RSK-1, -2, -3 [88-90]. MK5/PRAK was found to be expressed in most human tissues and activated by cellstressors and proinflammatory cytokines in vitro. In turn, PRAK activity was regulated by $\mathrm{p} 38 \alpha$ and $\mathrm{p} 38 \beta$ activity. Once activated, MK5/PRAK was reported to directly phosphorylate heat shock protein 27 (Hsp27) [91, 92], the latter having been implicated in several physiologically relevant immune-mediated inflammatory responses such as $\mathrm{CD}^{+}$ lymphocyte subset expansion and apoptosis resistance [93] as well as in the activation of the Toll-like receptor- 4 in monocyte-derived RA DCs [94]. Additionally, the conventional DMARD, methotrexate, was shown to enhance $\mathrm{PGD}_{2}$ stimulated Hsp27-induction in MC3T3-E1 osteoblasts at a point downstream of MAPKs [93]. MK5/PRAK was also shown to activate atypical ERK 3/4 [95], but the significance of this pathway in inflammatory arthritis remains unclear. However, the MK5/PRAK promoters of human, mouse and rat all contain a cyclic AMP (cAMP) responsive element that binds to CREB in vitro [96], indicating that molecules involved in inflammatory arthritis that also activate cAMPdependent protein kinase $\mathrm{A}$ (e.g., $\mathrm{PGE}_{2}$ ), may also upregulate MK5/PRAK transcription.

It was suggested that novel upstream p $38 \alpha$-specific SMIs, such as SD-282 (indole-5-carboxamide) could potentially be useful inhibitors of p38 $\alpha$-driven inflammation [97]. Thus, p38 $\alpha$ inhibition by SD-282 may also affect downstream
MK5/PRAK-driven p38 kinase-regulated pathways as well [98]. Additionally, Sun et al. [99] reported that PRAK activated the tumor suppressor p53 by direct phosphorylation. Although it has not been directly determined, PRAK may therefore also be also involved in p53-mediated transactivation activity of inflammatory response genes, such as $\mathrm{PGE}_{2}$ [100], as well as playing a role in the regulation of murine CIA responses [101]. In the latter, Type II collagen-stimulated T-cell activation and IFN- $\gamma$ production ex vivo was significantly higher in p53 null mice with CIA compared to their wild-type counterparts [101]. An experimental inhibitor of MK5/PRAK, GLPG0259, was reported to provide "excellent" protection against bone erosion as well as reducing inflammation in an RA animal model [102].

\section{Micro RNAs}

Micro- RNAs (miRs) are small noncoding RNA molecules composed of double-stranded RNAs of 21-25 nucleotides derived from endogenously expressed transcripts with characteristic hairpin structures (Figure 4). miRs are known to negatively regulate gene expression at the posttranscriptional level [103, 104]. Lewis et al. [105] first proposed that perhaps as much as one-third of all mRNAs were targets for miRmediated regulation. In the context of the putative epigenetic role for miRs in regulating the inflammatory response in RA [106], Taganov et al. [107] showed that miR-146a/b, miR-132 and miR-155 were endotoxin-responsive. Moreover, miR146 a was also found to be an NF- $\kappa \mathrm{B}$-responsive gene with miR146a/b predicted to interact with sequences of the $3^{\prime}$ untranslated region of TNF-associated factor-6 (TRAF6) and IL-1 receptor-associated kinase-1 (IRAK-1) genes which are 2 key adaptor molecules intimately involved in the 
TABLE 1: Some novel experimental therapies alter the severity of arthritis in animal models.

\begin{tabular}{|c|c|c|c|c|}
\hline Target & Drug & Animal Model & Results & Reference \\
\hline Spleen Tyrosine Kinase & R788/R406 & Murine $\mathrm{CIA}^{\dagger}$ & $\begin{array}{l}\downarrow \text { Arthritis } \\
\downarrow \text { Cytokines }\end{array}$ & {$[68]$} \\
\hline MEK & PD184352 & Murine CIA & $\begin{array}{c}\downarrow \text { Arthritis } \\
\downarrow \text { Proteoglycan degradation }\end{array}$ & {$[82]$} \\
\hline ERK & FR180294 & Murine CIA & $\begin{array}{c}\downarrow \text { T cell activation } \\
\uparrow \text { Apoptosis }\end{array}$ & {$[83]$} \\
\hline $\operatorname{miR}-15 a$ & $\operatorname{miR}-15 a$ & Murine Autoantibody ${ }^{\ddagger}$ & $\begin{array}{c}\downarrow \text { bcl-2 } \\
\uparrow \text { caspase-3 }\end{array}$ & {$[85]$} \\
\hline TRAIL & rhTRAIL* & Rabbit IL- $1 \beta$-transfected fibroblasts** & $\begin{array}{c}\uparrow \text { Apoptosis } \\
\downarrow \text { Lymphocyte infiltration } \\
\downarrow \text { Arthritis }\end{array}$ & {$[86]$} \\
\hline Proteasome & Bortezomib & Murine CIA & $\begin{array}{c}\downarrow \text { TNF- } \alpha, \text { IL- } 1 \beta, \text { IL-6,iNOS, COX-2 } \\
\downarrow \text { MMP-3 }\end{array}$ & {$[87]$} \\
\hline
\end{tabular}

$\dagger$ Type II Collagen-Induced Arthritis

₹ FAM-atelocollagen + miR-15a

* Recombinant human TRAIL

** IL-1 $\beta$-transfected human fibroblasts engrafted into rabbit synovial joint.

regulation of the Toll-like receptor (TLR) and cytokine receptor pathways. Thus, expression of the miR146a/b could be expected to alter the functional regulation of these signaling pathways. Another piece of the miR story with specific relevance to inflammatory arthritis emerged when O'Connell et al. [108] demonstrated that miR-155 was the only miR to be upregulated in monocyte cultures by either polyriboinosinic acid:polyribocytidylic acid [poly (I:C)], a synthetic ligand that activates the TLR pathway, and interferon- $\beta$ (IFN- $\beta$ ). TLR ligands that induced miR- 155 also required myeloid differentiation factor 88 (MyD88) or the TIR-domain-containing adapter-inducing IFN- $\beta$ (TRIF)associated TLR3/TLR4 molecules. Furthermore, inhibition of c-Jun-N-terminal kinase (JNK) blocked miR-155 induction induced by [poly (I:C)] or TNF- $\alpha$.

These initial studies provided the impetus for considering miRs as potential novel experimental targets in inflammatory arthritis. In that regard, Nakasa et al. [110] showed that mature miR146a and primary miR146a/b were highly expressed in RA synovial tissue where it was principally found in $\mathrm{CD}^{+} 8^{+}$macrophages with a smaller percentage of $\mathrm{CD}^{+} \mathrm{T}$-cells and $\mathrm{CD} 79 \mathrm{a}^{+}$early progenitor B-cells also producing miR146a/b. In vitro miR146a/b was markedly upregulated in RA-SF by TNF- $\alpha$ and IL- $1 \beta$, an indicator that high levels of these proinflammatory cytokines found in RA synovial fluid were likely to be responsible for the elevated level of miR146a/b found in RA synovial tissue. Stanczyk et al. [111] confirmed the basic findings of O'Connell et al. [108] and Nasaka et al. [110] and further showed higher levels of miR-146a and miR-155 in RA synovial tissue compared to synovial tissue from patients with osteoarthritis. Furthermore, Stanczyk et al. [111] showed that forced expression of miR-155 repressed the levels of MMP-3 (stromelysin-1) produced by RA-SF. miR-155 also reduced the expression of MMP-1 (collagenase1) and MMP-3 induced by TLR ligands, TNF- $\alpha$, IL- $1 \beta$, [poly (I:C)] and bacterial lipoprotein. More recently, elevated expression of miR-146a, miR-155, miR-132, miR-16, but not miR-let-7a expression was found in RA synovium [112] with elevated miR-146a levels also found in circulating RA monocytes. Interestingly, TRAF6, and IRAK-1, two targets of miR-146a [107] were produced at similar levels in RA and control monocytes, despite the finding of increased miR-146 expression by RA monocytes. This result suggested that miR-146a produced by RA monocytes was apparently nonfunctional. As such, defective miR-146a could contribute to the dysregulation of TNF- $\alpha$-signaling in RA since repression of TRAF6 and IRAK-1 in THP-1 cells resulted in an $86 \%$ reduction in TNF- $\alpha$. Finally, Nagata et al. [85] showed in an autoantibody-induced model of murine inflammatory arthritis in DBA/1 mice that double-stranded miR15a coadministered intra-articularly with FAM-atelocollagen complex resulted in elevated expression of miR-15a in the arthritic mouse synovium compared to mice injected with siRNA-atelocollagen complex representing the control group. Interestingly, the antiapoptotic protein bcl-2 was downregulated by miR-15a whereas caspase- 3 was increased by miR15-a in the mice with autoantibody-induced arthritis compared to the control group. These results suggested that experimental therapy with miR-15a was capable of inducing caspase-3-dependent apoptosis in RA synovium by suppressing bcl-2 expression.

\section{Tumor Necrosis Factor-Related Apoptosis-Inducing Ligand Receptors}

The failure of apoptosis to rectify aberrant cellular proliferation signals that activate synoviocytes, $\mathrm{T}-$ and $\mathrm{B}-$ cells, macrophages and osteoclasts is a signature event in various forms of inflammatory arthritis [36, 37]. Several intracellular processes have been identified as being defective in the regulation of apoptosis in inflammatory arthritis. 


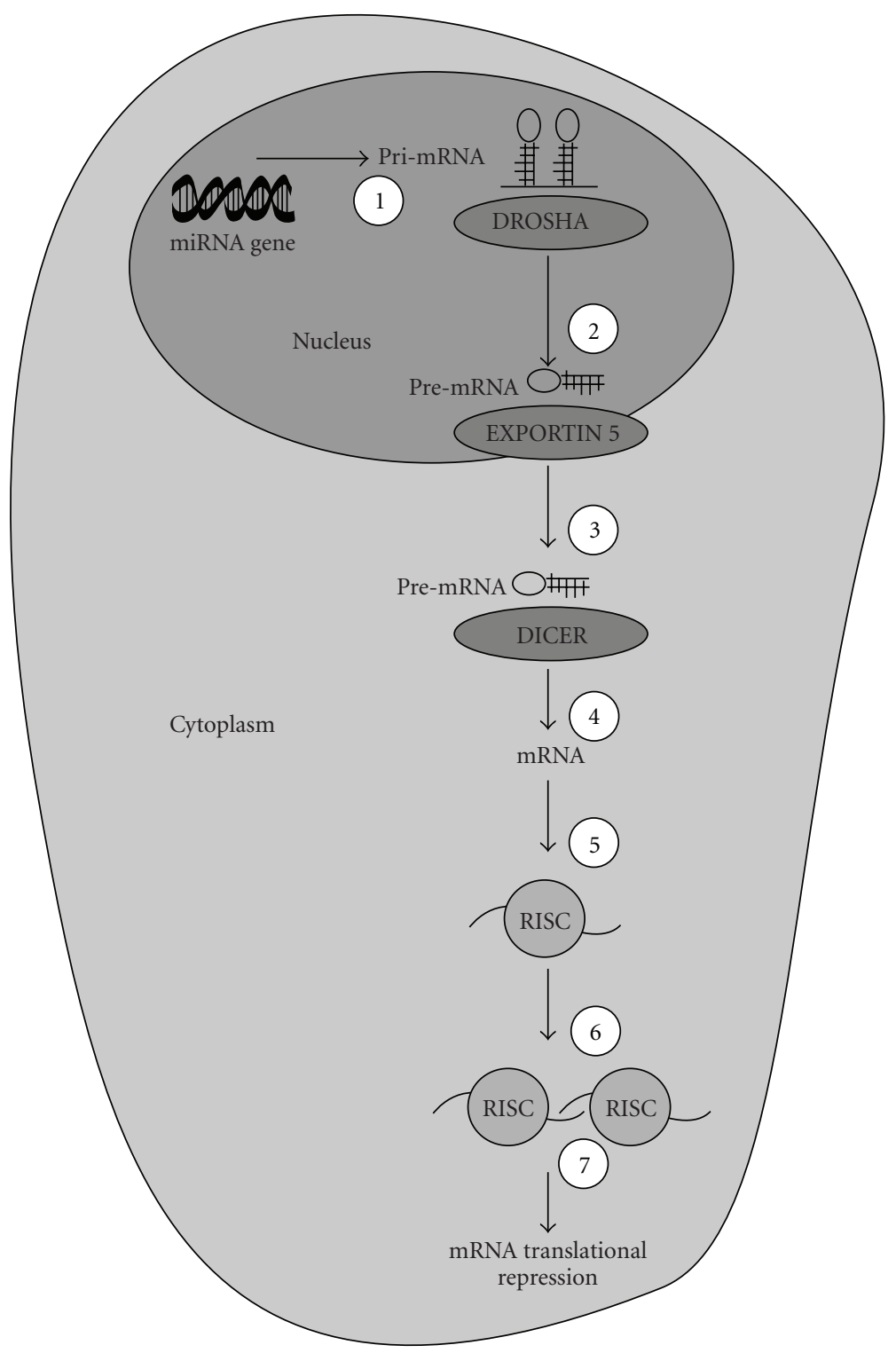

FIgure 4: The miR Pathway. Step 1 of the miR pathway involves the transcription of a 70-100 nucleotide (nt) pri-miR from an miR gene which is then processed in the nucleus via Step 2 by the RNAse III enzyme, DROSHA to yield pre-miR. Following the transport of pre-miR from the nucleus to the cytoplasm mediated by the nuclear export receptor protein, EXPORTIN 5 at Step 3, a second RNAse III enzyme, DICER, digests pre-miR at Step 4 resulting in a 21-25 nt miR. At this juncture, miR has the capacity to bind to the RNA-Induced Silencing Complex (RISC) and at Steps 5 and 6 aligns itself with an mRNA. The final step (Step 7) is dependent on whatever complimentarity exists between a miR and a target sequence in mRNA. Therefore, the degree of complimentarity between a miR and an mRNA results in either translational repression or mRNA cleavage (reviewed in [109]).

These include, the prominence of the PI3K/PTEN/Akt cell survival pathway $[113,114]$, upregulation of HSP70 gene expression [115], suppressed Fas/CD95-mediated signaling [116], activation of NF- $\kappa \mathrm{B}[117,118]$ by the proinflammatory cytokines, IL- $1 \beta$ and TNF- $\alpha$ [119], by reactive oxygen species and nitrogen reactive species [120] as well as the activity of antiapoptotic BH3-proteins of the bcl-2 family [37, 121], all of which dampen the apoptosis signaling cascade. Despite the potential that these cellular events could be targeted for intervention in inflammatory arthritis, recent attention has been mainly focused on the critical role of tumor necrosis factor- (TNF-) related apoptosis-inducing ligand (TRAIL) as a target for elevating the frequency of apoptosis in immune-mediated inflammatory cells primarily because agonist TRAIL-receptor-specific antibodies have shown encouraging results in promoting apoptosis in cancer cells in some clinical trials [122].

Morel et al. [123] first showed that TRAIL induced RASF proliferation through activation of MAPK and PI3K/Akt since RA-SF proliferation could be inhibited by the ERK $1 / 2$ SMI, PD98059, the p38 kinase SMI, SB203580 and the PI3K/Akt SMI, LY294002, respectively. TRAIL also induced 
apoptosis in about one-third of the cells but in the cells that survived, TRAIL promoted RA-SF proliferation. Of note, TRAIL-mediated RA-SF proliferation could be blocked by neutralizing anti-TRAIL antibody. Trichostatin A (TSA), a Streptomyces metabolite which specifically inhibits mammalian histone deacetylases was shown to sensitize RA-SF to TRAIL-induced apoptosis, whereas TRAIL or TSA alone were unable to induce RA-SF apoptosis [124]. The results of this study suggested that the initial small apoptotic response of RA-SF to TRAIL reported by Morel et al. [123] may have been due to the presence of inactive sites in the cascade of TRAIL-signaling that were uncovered by administering TSA which resulted in an increase in the frequency of apoptotic cells.

Monocyte production of IFN- $\gamma$ also appeared to be critical in the dampening of TRAIL-mediated apoptosis in RA [125]. In that study which employed RA-FLS, IFN$\gamma$ rapidly phosphorylated STAT-1, -3 and -6 as well as ERK $1 / 2$ but not Akt or NF- $\kappa$ B p65. Interestingly, chemical inhibition of ERK 1/2 by PD98059 failed to overcome IFN$\gamma$-induced suppression of TRAIL-mediated apoptosis. Furthermore, IFN- $\gamma$-mediated inhibition of TRAIL-signaling could not be accounted for by significant changes in TRAIL$\mathrm{R}$, procaspases-3,-8,-9, Fas-activated death domain protein (FADD), tumor necrosis factor receptor 1-associated death domain protein, silencer of death domain protein, FADDlike-interleukin- $1 \beta$ converting enzyme (FLICE) inhibitory protein, bcl-2, Bcl-xL or Bax activity. These results suggested that IFN- $\gamma$ probably caused apoptosis resistance in RA-FLS in response to TRAIL by activating the JAK/STAT pathway. Although the precise mechanism accounting for IFN- $\gamma$ induced suppression of TRAIL-signaling beyond activation of STAT proteins in RA-FLS remains unknown, several more recent studies have addressed other aspects of apoptosis resistance in continuously proliferating cancer cells induced by INF- $\gamma$, Thus, Bonmort et al. [126] showed that DCs also synthesize INF- $\gamma$. Further, inhibitors of the c-kit tyrosine kinase in combination with IL-2 were shown to promote DC-mediated cytotoxicity of these tumor cells by TRAILmediated and IFN- type IIR-mediated pathways.

Epigenetic silencing of caspase- 8 activity can also result in apoptosis resistance. In that regard, Häcker et al. [127] showed that inhibitors of histone deacetylase activity, including, valproic acid, suberoylanilide hydroxamic acid/Vorinostat, and MS-275 cooperate with IFN- $\gamma$ to upregulate caspase- 8 in medulloblastoma cells lacking caspase- 8 , and restore TRAIL-mediated cytotoxicity. In future studies, it will be interesting to determine the extent to which valproic acid, suberoylanilide hydroxamic acid or MS-275 can restore IFN- $\gamma$ suppression of TRAIL-mediated signaling in RA-FLS.

In another line of investigation, Audo et al. [128] recently showed that TRAIL-induced apoptosis was inhibited in RA-FLS by the overexpression of the cell survival regulator proteins, $\mathrm{p} 21, \mathrm{X}$-inhibitor of apotosis protein, MCP1 and receptor-interacting protein. Furthermore, caspase8 played a crucial role in mediating TRAIL-induced RAFLS proliferation. Of note, TRAIL was shown to induce the breakdown of p21 and p27 that were both caspasedependent, but independent of ERK 1/2, p38 kinase and
PI3K/Akt activity. Additionally, Pundt et al. [129] showed that FasL- and TRAIL-mediated apoptosis in RA-SF cultures was cell-cycle dependent. Thus, future studies should take into consideration the pleiotypic nature of TRAIL-mediated signaling as well as perhaps targeting cell cycle-regulating genes in order to more appropriately define interventional strategies for employing TRAIL agonists in vivo.

Gene transfer and intra-articular administration of TRAIL have recently been employed to test the extent to which these strategies could modulate TRAIL-mediated apoptosis resistance in RA. Terzioglu et al. [130] employed adenoviral human TRAIL (i.e., Ad5hTRAIL) gene transfer in an attempt to overcome TRAIL-induced apoptosis resistance in primary synovial cell cultures obtained from RA patients. They reported that TRAIL-R was permissive for TRAILinduced apoptosis. However, high levels of TRAIL-R4 decoy receptor expression correlated with TRAIL resistance. Of note, decoy receptor-2 (DcR2) a TRAIL-R and a target for p53 siRNA [131], but only in combination with Ad5hTRAIL, eliminated the TRAIL-induced resistance to apoptosis in these cells to a more significant extent than when the cells were transfected with Ad5hTRAIL alone. Thus, the results of this study suggested that modulation of TRAIL-R expression could enable RA synoviocytes to be sensitized to TRAILmediated signaling. Furthermore, TRAIL gene transfer may be a useful strategy to test in animal models of RA to examine the extent to which apoptosis induction in synoviocytes ameliorates arthritis severity. Employing a different experimental strategy, Yao et al. [86] attempted to induce synovial cell apoptosis in a rabbit model of experimental arthritis induced by intra-articular administration of allogeneic fibroblasts that were genetically engineered to oversecrete human IL- $1 \beta$. Arthritic rabbits were then treated either by intra-articular administration of recombinant chimeric human TRAIL (rhTRAIL) or with saline. The TUNEL assay demonstrated extensive synovial cell apoptosis in the rabbits treated with rhTRAIL compared to the saline control group and a $50 \%$ reduction in lymphocyte infiltration in the inflamed joint. Furthermore, intra-articular administration of rhTRAIL altered neither the proteoglycan content of articular cartilage nor liver function. Taken together, the results of these studies suggested that a gene transfer strategy approach, keeping in mind the appropriate caveats needed to extend these experimental studies to clinical use [132], or administration of rhTRAIL might be capable of overcoming synoviocyte apoptosis resistance in RA.

\section{Inhibition of Proteasome Activity}

Proteasomes are large protein complexes that reside in both the nucleus and cytoplasm of eukaryotic cells [134]. A principal function of the 26S-proteasome is to regulate the concentration of completed proteins within a cell as well as to participate in the controlled degradation of misfolded proteins that is independent of enzyme activity within lysosomes [135] (Figure 5). In that regard, proteins destined for degradation in the proteasome are tagged with ubiquitin via a reaction that is catalyzed by ubiquitin ligases. 


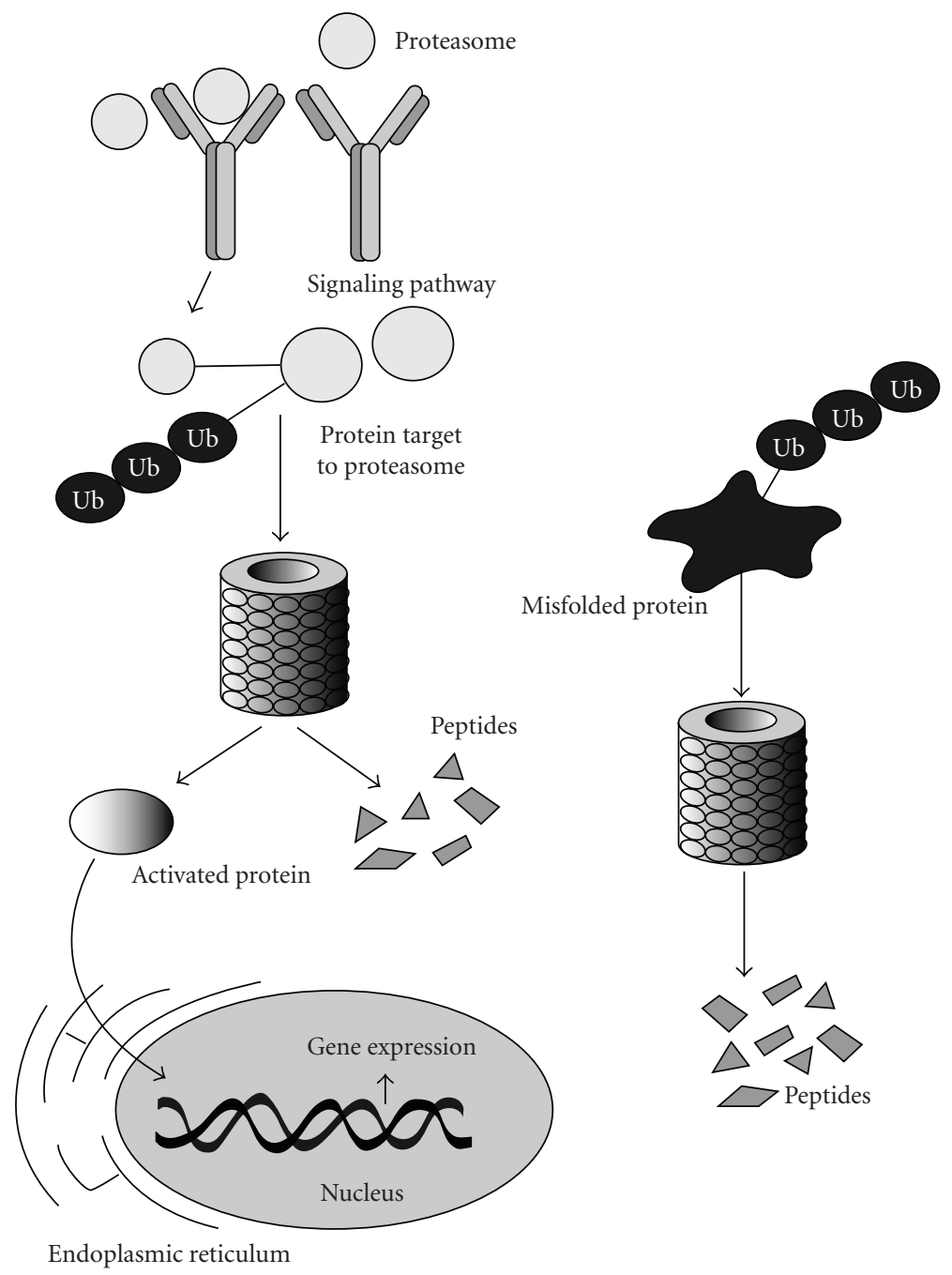

Figure 5: The Proteasome Signaling Pathway. Normally produced (left) or misfolded (right) proteins that are destined for 28S proteasomemediated degradation are targeted for degradation either by phosphorylation (P) or after tagging with ubiquitin (Ub), via ubiquitin ligase [133]. In this pathway, a polyubiquitin protein chain becomes bound to the $28 \mathrm{~S}$ proteasome providing a mechanism required for protein degradation. Nonphosphorylated or non-Ub-tagged proteins (i.e., "activated proteins") can bypass the proteasome pathway and be transported to the nucleus.

A polyubiquitin chain is formed which becomes bound to the proteasome and provides the required structural component for initiating proteasome-mediated degradation. Because the proteasome regulates so many of the fundamental cellular processes that may result in aberrant proteins participating in cell cycle progression, proliferation, protein trafficking, apoptosis and immune-mediated inflammatory processes [135], inhibition of the proteasome pathway has become a promising focus of research for modulating key components of dysfunctional protein function in cancer and immune cell signaling [136-138].

Prosurvival cell growth factors including, mutated p53, the E3 ubiquitin ligase hrd1, the ubiquitin-like protein sentrin, and NF- $\kappa \mathrm{B}$ were found to be increased in the pannus of RA synovial joints [139]. Thus, the increased concentration of these molecules is likely to be responsible for the fact that apoptosis is rarely detected in this tissue [36, 37]. Additionally, the continued uncontrolled growth of RA pannus despite the use of potent conventional and biologic DMARDs is likely to be responsible for the accelerated destruction of cartilage and bone in this disorder [38].

PS-341 (bortezomib) is a newly developed proteasome inhibitor which induced apoptosis in cancer cells by inhibiting the activity of the Forkhead BoxM1 (FoxM1) transcription factor [140]. In that regard, overexpression of FoxM1 was shown to specifically override bortezomibinduced-apoptosis, but not doxorubicin-induced cancer cell apoptosis. More recently, bortezomib was shown to activate the mitochondrial pathway of apoptosis in activated $\mathrm{CD}^{+}{ }^{+}$T-cells which was characterized by the accumulation of proapoptotic proteins, including, p53 upregulated modulator of apoptosis (PUMA), the bcl-2 protein family members, Noxa and Bim as well as p53 in the mitochondrial outer membrane [141]. Bortezomib also induced apoptosis and inhibited NF- $\kappa$ B-dependent cytokine production by activated T-cells isolated from RA patients [142]. These 
cytokines included, TNF- $\alpha$, IL- $1 \beta$ and IL- 6 and IL-10. However, the effect of bortezomib on regulating the ratio of accumulated proinflammatory and antiinflammatory cytokines via inhibition of NF- $\kappa \mathrm{B}$ [143] in vitro will require further study.

In addition, the extent to which bortezomib might alter the activity of the newly described "secreted osteoclastogenic factor of activated T-cells" (SOFAT), a factor relevant in bone destruction in RA, distinct from RANKL [144], should be examined.

The use of putative proteasome inhibitors for regulating autoimmune arthritis-related pathophysiology was further complicated when Kwak et al. [145] recently showed that mg132, a selective proteasome inhibitor, $\left(K_{i}=4 \mathrm{nM}\right)$ that inhibits $\mathrm{I} \kappa \mathrm{B}$ degradation and N-Acetyl-Leu-Leu-NleCHO (ALLN), a calpain inhibitor, both enhanced ERK 1/2 and Akt activation resulting in osteoclast survival under conditions of survival factor deprivation.

In murine CIA, bortezomib administered by intraperitoneal injection significantly reduced the severity of arthritis and stabilized joint structure architecture while also suppressing the production of several biomarkers of immunemediated inflammation, including, TNF- $\alpha$, IL- $1 \beta$, and IL- 6 , COX-2, and inducible nitric oxide synthase (iNOS) as well as inhibiting MMP-3 synthesis [87]. No blood cell, liver or kidney toxicity from was reported in the CIA mice treated with bortezomib. These results suggested that proteasome inhibition is worthy of additional study to determine the extent to which it may become a useful adjunctive strategy for regulating immune-mediated inflammatory arthritis.

\section{Conclusions}

In vitro cultures of immune cells and synovial fibroblasts from nonarthritic and RA patients as well as well-validated animal models of inflammatory arthritis have been employed to test novel experimental strategies for attenuating proinflammatory cytokine production, MMP biosynthesis, Tcell and B-cell activity and inducing apoptosis as well assessing some compounds for their capacity to dampen the severity of clinical measures of arthritis. The discovery of promising specific targets for intervention in the inflammatory arthritis process have included, S1P, IL-7R, Syk, Raf/MEK/ERK 1/2, MK5/PRAK, miRNA, PI3K/PTEN/Akt, NF- $\kappa \mathrm{B}$, TRAIL/TRAIL-R and the $28 \mathrm{~S}$ proteasome. Altering the biological activity of several of these targets has shown efficacy for reducing inflammation-related pathways especially when employed in animal models of inflammatory arthritis (Table 1). The results of these studies make it highly likely that the discovery of some of these novel targets will eventually make their way into arthritis clinical trials.

\section{Abbreviations}

$\begin{array}{ll}\text { BCR: } & \text { B-cell receptor } \\ \text { BH3: } & \text { Bcl-2 homolog-3 } \\ \text { COX-2: } & \text { Cyclooxygenase-2 } \\ \text { CREB: } & \text { Cyclic AMP responsive element } \\ & \text { binding protein }\end{array}$

\begin{tabular}{|c|c|}
\hline CTLA-4: & Cytotoxic T-lymphocyte antigen-4 \\
\hline DcR-2: & decoy receptor- 2 \\
\hline DMARD: & $\begin{array}{l}\text { Disease modifying antirheumatic } \\
\text { drug }\end{array}$ \\
\hline FADD: & Fas-activated death domain \\
\hline FLICE: & $\begin{array}{l}\text { FADD-like interleukin-1 converting } \\
\text { enzyme }\end{array}$ \\
\hline FoxM1: & Forkhead box M1 \\
\hline FoxP3: & Forkhead box P3 \\
\hline GPCR: & G-protein coupled receptor \\
\hline IL-1 $\beta$ : & interleukin- $1 \beta$ \\
\hline IL-6/IL-6R: & Interleukin-6/Interleukin-6 receptor \\
\hline $\begin{array}{l}\text { IL-7/IL-7R: } \\
\text { INF- } \beta / \gamma:\end{array}$ & $\begin{array}{l}\text { Inteleukin-7/Interleukin-7 receptor } \\
\text { interferon- } \beta / \gamma\end{array}$ \\
\hline IRAP: & $\begin{array}{l}\text { interleukin-1 receptor antagonist } \\
\text { protein }\end{array}$ \\
\hline iNOS: & inducible nitric oxide synthase \\
\hline IRAK-1: & IL-1 receptor-associated kinase-1 \\
\hline JAK/STAT: & $\begin{array}{l}\text { Janus kinase/signal transducers and } \\
\text { activators of transcription }\end{array}$ \\
\hline JIA: & Juvenile idiopathic arthritis \\
\hline JNK: & C-Jun-amino terminal kinase \\
\hline KC-Gro- $\alpha$ : & $\begin{array}{l}\text { Keratinocyte cotton rat } \\
\text { growth-regulated protein- } \alpha\end{array}$ \\
\hline MCP-1: & $\begin{array}{l}\text { macrophage chemoattractant } \\
\text { protein-1 }\end{array}$ \\
\hline miRNA: & microRNA \\
\hline MK5/PRAK: & $\begin{array}{l}\text { mitogen-activated protein kinase } \\
\text { 5/p38 kinase regulated/activated } \\
\text { protein kinase }\end{array}$ \\
\hline MMP: & matrix metalloproteinase \\
\hline MyD88: & myeloid differentiation factor- 88 \\
\hline $\mathrm{NF}-\kappa \mathrm{B}:$ & nuclear factor- $\kappa \mathrm{B}$ \\
\hline PI3K/PTEN/Akt: & $\begin{array}{l}\text { Phosphoinositide-3- } \\
\text { kinase/phosphatase and tensin } \\
\text { homolog/serine-threonine kinase Akt }\end{array}$ \\
\hline $\mathrm{PGE}_{2}$ : & Prostaglandin $\mathrm{E}_{2}$ \\
\hline RA: & Rheumatoid arthritis \\
\hline RA-FLS: & $\begin{array}{l}\text { Rheumatoid arthritis-fibroblast-like } \\
\text { synoviocytes }\end{array}$ \\
\hline $\begin{array}{l}\text { Raf/MEK } 1 / 2 / \\
\text { ERK } 1 / 2:\end{array}$ & $\begin{array}{l}\text { Raf/MAPK kinase } 1 / 2 \text { /extracellular } \\
\text { signal-regulated kinase } 1 / 2\end{array}$ \\
\hline RANKL: & $\begin{array}{l}\text { receptor activator of nuclear factor } \\
\kappa B \text { ligand }\end{array}$ \\
\hline RISC: & RNA-induced silencing complex \\
\hline SAP/MAPK: & $\begin{array}{l}\text { Stress-activated } \\
\text { protein/mitogen-activated protein } \\
\text { kinase }\end{array}$ \\
\hline SMI: & small molecule inhibitor \\
\hline SOFAT: & $\begin{array}{l}\text { Secreted osteoclastogenic factor } \\
\text { secreted of activated T-cells }\end{array}$ \\
\hline SphK-1/2: & Sphingosine kinase-1/2 \\
\hline S1P: & sphingosine-1-phosphate \\
\hline SP1L: & Sp1 lyase \\
\hline SyK: & spleen tyrosine kinase \\
\hline TCR: & T-cell receptor \\
\hline TLR: & Toll-like receptor \\
\hline
\end{tabular}


TNF- $\alpha$ : Tumor necrosis factor- $\alpha$

TRAF-6: Tumor necrosis factor-associated factor-6

TRAIL: Tumor necrosis factor-related apoptosis-inducing ligand

ZAP-70: $\zeta$-chain-associated protein 70 .

\section{References}

[1] M. G. Feely, A. Erickson, and J. R. O’Dell, “Therapeutic options for rheumatoid arthritis," Expert Opinion on Pharmacotherapy, vol. 10, no. 13, pp. 2095-2106, 2009.

[2] L. G. Schipper, J. Fransen, P. Barrera, and P. L. C. M. van Riel, "Methotrexate in combination with sulfasalazine is more effective in rheumatoid arthritis patients who failed sulfasalazine than in patients naïve to both drugs," Rheumatology, vol. 48, no. 7, pp. 828-833, 2009.

[3] M. L. Hetland, K. Stengaard-Pedersen, P. Junker, et al., "Aggressive combination therapy with intra-articular glucocorticoid injections and conventional disease-modifying anti-rheumatic drugs in early rheumatoid arthritis: secondyear clinical and radiographic results from the CIMESTRA study," Annals of the Rheumatic Diseases, vol. 67, no. 6, pp. 815-822, 2008.

[4] M. Khraishi, "Comparative overview of safety of the biologics in rheumatoid arthritis," Journal of Rheumatology, vol. 36, supplement 82, pp. 25-32, 2009.

[5] L. J. Gibbons and K. L. Hyrich, "Biologic therapy for rheumatoid arthritis: clinical efficacy and predictors of response," BioDrugs, vol. 23, no. 2, pp. 111-124, 2009.

[6] D. E. Furst, "Certolizumab pegol—what role does this new TNF inhibitor have in the treatment of RA?" Nature Clinical Practice Rheumatology, vol. 5, no. 3, pp. 134-135, 2009.

[7] V. Oldfield and G. L. Plosker, "Golimumab: in the treatment of rheumatoid arthritis, psoriatic arthritis, and ankylosing spondylitis," BioDrugs, vol. 23, no. 2, pp. 125-135, 2009.

[8] M. Mertens and J. A. Singh, "Anakinra for rheumatoid arthritis," Cochrane Database of Systematic Reviews, no. 1, Article ID CD005121, 2009.

[9] L. Šenolt, J. Vencovský, K. Pavelka, C. Ospelt, and S. Gay, "Prospective new biological therapies for rheumatoid arthritis," Autoimmunity Reviews, vol. 9, no. 2, pp. 102-107, 2009.

[10] L. D. Church and M. F. McDermott, "Canakinumab, a fully-human mAb against IL- $1 \beta$ for the potential treatment of inflammatory disorders," Current Opinion in Molecular Therapeutics, vol. 11, no. 1, pp. 81-89, 2009.

[11] V. Goëb, M. H. Buch, E. M. Vital, and P. Emery, "Costimulation blockade in rheumatic diseases: where we are?" Current Opinion in Rheumatology, vol. 21, no. 3, pp. 244-250, 2009.

[12] B. Laganà, M. Vinciguerra, and R. D’Amelio, "Modulation of T-cell co-stimulation in rheumatoid arthritis: clinical experience with abatacept," Clinical Drug Investigation, vol. 29, no. 3, pp. 185-202, 2009.

[13] A. J. K. Ostör, "Abatacept: a T-cell co-stimulation modulator for the treatment of rheumatoid arthritis," Clinical Rheumatology, vol. 27, no. 11, pp. 1343-1353, 2008.

[14] S. Dass, E. M. Vital, and P. Emery, "Rituximab: novel B-cell depletion therapy for the treatment of rheumatoid arthritis," Expert Opinion on Pharmacotherapy, vol. 7, no. 18, pp. 25592570, 2006.

[15] M. Nakou, G. Katsikas, P. Sidiropoulos, et al., "Rituximab therapy reduces activated $\mathrm{B}$ cells in both the peripheral blood and bone marrow of patients with rheumatoid arthritis: depletion of memory B cells correlates with clinical response," Arthritis Research \& Therapy, vol. 11, no. 4, article R131, 2009.

[16] R. Caporali, M. Caprioli, F. Bobbio-Pallavicini, S. Bugatti, and C. Montecucco, "Long term treatment of rheumatoid arthritis with rituximab," Autoimmunity Reviews, vol. 8, no. 7, pp. 591-594, 2009.

[17] A. Finckh and C. Gabay, "At the horizon of innovative therapy in rheumatology: new biologic agents," Current Opinion in Rheumatology, vol. 20, no. 3, pp. 269-275, 2008.

[18] F. De Benedetti, "Targeting interleukin-6 in pediatric rheumatic diseases," Current Opinion in Rheumatology, vol. 21, no. 5, pp. 533-537, 2009.

[19] J. van der Heijden, M. C. de Jong, B. A. Dijkmans, et al., "Acquired resistance of human $\mathrm{T}$ cells to sulfasalazine: stability of the resistant phenotype and sensitivity to nonrelated DMARDs," Annals of the Rheumatic Diseases, vol. 63, no. 2, pp. 131-137, 2004.

[20] A. Gibofsky, W. R. Palmer, J. A. Goldman, et al., "Real-world utilization of DMARDs and biologics in rheumatoid arthritis: the RADIUS (Rheumatoid Arthritis Disease-Modifying Anti-Rheumatic Drug Intervention and Utilization Study) study," Current Medical Research and Opinion, vol. 22, no. 1, pp. 169-183, 2006.

[21] W. Kievit, J. Fransen, A. J. M. Oerlemans, et al., "The efficacy of anti-TNF in rheumatoid arthritis, a comparison between randomised controlled trials and clinical practice," Annals of the Rheumatic Diseases, vol. 66, no. 11, pp. 1473-1478, 2007.

[22] J. D. Greenberg, M. Kishimoto, V. Strand, et al., “Tumor necrosis factor antagonist responsiveness in a United States rheumatoid arthritis cohort," American Journal of Medicine, vol. 121, no. 6, pp. 532-538, 2008.

[23] C. Salliot, M. Dougados, and L. Gossec, "Risk of serious infections during rituximab, abatacept and anakinra treatments for rheumatoid arthritis: meta-analyses of randomised placebo-controlled trials," Annals of the Rheumatic Diseases, vol. 68, no. 1, pp. 25-32, 2009.

[24] J. P. Leombruno, T. R. Einarson, and E. C. Keystone, "The safety of anti-tumour necrosis factor treatments in rheumatoid arthritis: meta and exposure-adjusted pooled analyses of serious adverse events," Annals of the Rheumatic Diseases, vol. 68, no. 7, pp. 1136-1145, 2009.

[25] C. J. Malemud, "Defining novel targets for intervention in rheumatoid arthritis: an overview," Current Rheumatology Reviews, vol. 4, no. 4, pp. 214-218, 2008.

[26] C. J. Malemud and E. Pearlman, "Targeting JAK/STAT signaling pathway in inflammatory diseases," Current Signal Transduction Therapy, vol. 4, no. 4, pp. 201-221, 2009.

[27] C. J. Malemud, "Inhibitors of stress-activated protein/ mitogen-activated protein kinase pathways," Current Opinion in Pharmacology, vol. 7, no. 3, pp. 339-343, 2007.

[28] S. C. Karcher and S. A. Laufer, "Successful structure-based design of recent p38 MAP kinase inhibitors," Current Topics in Medicinal Chemistry, vol. 9, no. 7, pp. 655-676, 2009.

[29] T. Mima and N. Nishimoto, "Clinical value of blocking IL6 receptor," Current Opinion in Rheumatology, vol. 21, no. 3, pp. 224-230, 2009.

[30] C. J. Malemud, "Recent advances in neutralizing the IL-6 pathway in arthritis," Open Access Rheumatology: Research \& Reviews, vol. 1, no. 1, pp. 1-18, 2009.

[31] S. E. Alvarez, S. Milstien, and S. Spiegel, "Autocrine and paracrine roles of sphingosine-1-phosphate," Trends in 
Endocrinology and Metabolism, vol. 18, no. 8, pp. 300-307, 2007.

[32] A. J. Melendez, "Sphingosine kinase signalling in immune cells: potential as novel therapeutic targets," Biochimica et Biophysica Acta, vol. 1784, no. 1, pp. 66-75, 2008.

[33] A. Weigert, N. Weis, and B. Brüne, "Regulation of macrophage function by sphingosine-1-phosphate," Immunobiology, vol. 214, no. 9-10, pp. 748-760, 2009.

[34] I. Ishii, N. Fukushima, X. Ye, and J. Chun, "Lysophospholipid receptors: signaling and biology," Annual Review of Biochemistry, vol. 73, pp. 321-354, 2004.

[35] N. C. Hait, C. A. Oskeritzian, S. W. Paugh, S. Milstien, and S. Spiegel, "Sphingosine kinases, sphingosine 1-phosphate, apoptosis and diseases," Biochimica et Biophysica Acta, vol. 1758, no. 12, pp. 2016-2026, 2006.

[36] C. J. Malemud and H. J. Gillespie, "The role of apoptosis in arthritis," Current Rheumatology Reviews, vol. 1, no. 2, pp. 131-142, 2005.

[37] J. Hutcheson and H. Perlman, "Apoptotic regulators and RA," Current Rheumatology Reviews, vol. 4, no. 4, pp. 254-258, 2008.

[38] C. J. Malemud and M. E. Schulte, "Is there a final common pathway for arthritis?" Future Rheumatology, vol. 3, no. 3, pp. 253-268, 2008.

[39] Y. Kariya, A. Kihara, M. Ikeda, et al., "Products by the sphingosine kinase/sphingosine 1-phosphate (S1P) lyase pathway but not S1P stimulate mitogenesis," Genes to Cells, vol. 10, no. 6, pp. 605-615, 2005.

[40] J. T. Bagdanoff, M. S. Donoviel, A. Nouraldeen, et al., "Inhibition of sphingosine-1-phosphate lyase for the treatment of autoimmune disorders," Journal of Medicinal Chemistry, vol. 52, no. 13, pp. 3941-3953, 2009.

[41] A. Billich and T. Baumruker, "Sphingolipid metabolizing enzymes as novel therapeutics," Subcellular Biochemistry, vol. 49, pp. 487-522, 2008.

[42] http://www.mskreport.com/articles.cfm?articleID=3416.

[43] B. J. Pettus, J. Bielawski, A. M. Porcelli, et al., "The sphingosine kinase 1/sphingosine-1-phosphate pathway mediates COX-2 induction and $\mathrm{PGE}_{2}$ production in response to TNF$\alpha$," FASEB Journal, vol. 17, no. 11, pp. 1411-1421, 2003.

[44] D. Mechtcheriakova, A. Wlachos, J. Sobanov, et al., "Sphingosine 1-phosphate phosphatase 2 is induced during inflammatory responses," Cellular Signalling, vol. 19, no. 4, pp. 748-760, 2007.

[45] K. Akashi, M. Kondo, and I. L. Weissman, "Role of interleukin-7 in T-cell development from hematopoietic stem cells," Immunological Reviews, vol. 165, pp. 13-28, 1998.

[46] M. Saini, C. Pearson, and B. Seddon, "Regulation of T celldendritic cell interactions by IL-7 governs T-cell activation and homeostasis," Blood, vol. 113, no. 23, pp. 5793-5800, 2009.

[47] T. K. Vogt, A. Link, J. Perrin, D. Finke, and S. A. Luther, "Novel function for interleukin-7 in dendritic cell development," Blood, vol. 113, no. 17, pp. 3961-3968, 2009.

[48] S. Schmutz, N. Bosco, S. Chappaz, et al., "Cutting edge: IL7 regulates the peripheral pool of adult ROR $\gamma^{+}$lymphoid tissue inducer cells," Journal of Immunology, vol. 183, no. 4, pp. 2217-2221, 2009.

[49] A. H. Banham, "Cell-surface IL-7 receptor expression facilitates the purification of $\mathrm{FOXP}^{+}$regulatory T cells," Trends in Immunology, vol. 27, no. 12, pp. 541-544, 2006.

[50] P. M. Appasamy, "Biological and clinical implications of interleukin-7 and lymphopoiesis," Cytokines, Cellular and Molecular Therapy, vol. 5, no. 1, pp. 25-39, 1999.
[51] C. J. Malemud and S. K. Reddy, "Targeting cytokines, chemokines and adhesion molecules in rheumatoid arthritis," Current Rheumatology Reviews, vol. 4, no. 4, pp. 219-234, 2008.

[52] K. Akashi, M. Kondo, U. von Freeden-Jeffry, R. Murray, and I. L. Weissman, "Bcl-2 rescues T lymphopoiesis in interleukin7 receptor-deficient mice," Cell, vol. 89, no. 7, pp. 1033-1041, 1997.

[53] A. R. Khaled, W. Q. Li, J. Huang, et al., "Bax deficiency partially corrects interleukin-7 receptor $\alpha$ deficiency," Immunity, vol. 17, no. 5, pp. 561-573, 2002.

[54] E. Sitnicka, C. Brakebusch, I.-L. Martensson, et al., "Complementary signaling through flt 3 and interleukin-7 receptor $\alpha$ is indispensable for fetal and adult B cell genesis," Journal of Experimental Medicine, vol. 198, no. 10, pp. 1495-1506, 2003.

[55] S. M. Churchman and F. Ponchel, "Interleukin-7 in rheumatoid arthritis," Rheumatology, vol. 47, no. 6, pp. 753-759, 2008.

[56] S.-I. Sawa, D. Kamimura, G.-H. Jin, et al., "Autoimmune arthritis associated with mutated interleukin (IL)-6 receptor gp130 is driven by STAT3/IL-7-dependent homeostatic proliferation of CD4+ T cells," Journal of Experimental Medicine, vol. 203, no. 6, pp. 1459-1470, 2006.

[57] H.-R. Kim, K.-A. Hwang, S.-H. Park, and I. Kang, "IL-7 and IL-15: biology and roles in T-cell immunity in health and disease," Critical Reviews in Immunology, vol. 28, no. 4, pp. 325-339, 2008.

[58] S. A. Y. Hartgring, J. W. J. Bijlsma, F. P. J. G. Lafeber, and J. A. G. van Roon, "Interleukin-7 induced immunopathology in arthritis," Annals of the Rheumatic Diseases, vol. 65, supplement 3, pp. iii69-iii74, 2006.

[59] J. A. G. van Roon, S. A. Y. Hartgring, M. W.-V. Wijk, et al., "Persistence of interleukin 7 activity and levels on tumour necrosis factor $\alpha$ blockade in patients with rheumatoid arthritis," Annals of the Rheumatic Diseases, vol. 66, no. 5, pp. 664-669, 2007.

[60] S. A. Y. Hartgring, J. A. G. van Roon, M. W. V. Wijk, et al., "Elevated expression of interleukin-7 receptor in inflamed joints mediates interleukin-7-induced immune activation in rheumatoid arthritis," Arthritis and Rheumatism, vol. 60, no. 9, pp. 2595-2605, 2009.

[61] N. K. Vudattu, S. Kuhlmann-Berenzon, M. Khademi, V. Seyfert, T. Olsson, and M. J. Maeurer, "Increased numbers of IL-7 receptor molecules on CD4+CD25-CD107a+ T-cells in patients with autoimmune diseases affecting the central nervous system," PLoS ONE, vol. 4, no. 8, article e6534, 2009.

[62] C. J. Malemud, "Role of nonreceptor tyrosine and threonine kinase inhibitors," in Molecular Biology of Cancer: Toward New Therapies, J. García-Foncillas, Ed., pp. 537-555, Prous Science, Barcelona, Spain, 2009.

[63] B. R. Wong, E. B. Grossbard, D. G. Payan, and E. S. Masuda, "Targeting Syk as a treatment for allergic and autoimmune disorders," Expert Opinion on Investigational Drugs, vol. 13, no. 7, pp. 743-762, 2004.

[64] N. Rao, A. K. Ghosh, S. Ota, et al., "The non-receptor tyrosine kinase Syk is a target of Cbl-mediated ubiquitylation upon B-cell receptor stimulation," EMBO Journal, vol. 20, no. 24, pp. 7085-7095, 2002.

[65] A. G. Tristano, "Tyrosine kinases as targets in rheumatoid arthritis," International Immunopharmacology, vol. 9, no. 1, pp. 1-9, 2009.

[66] M. Bajpai, P. Chopra, S. G. Dastidar, and A. Ray, "Spleen tyrosine kinase: a novel target for therapeutic intervention 
of rheumatoid arthritis," Expert Opinion on Investigational Drugs, vol. 17, no. 5, pp. 641-659, 2008.

[67] M. Hikida, S. Casola, N. Takahashi, et al., "PLC- $\gamma 2$ is essential for formation and maintenance of memory B cells," Journal of Experimental Medicine, vol. 206, no. 3, pp. 681-689, 2009.

[68] P. R. Pine, B. Chang, N. Schoettler, et al., "Inflammation and bone erosion are suppressed in models of rheumatoid arthritis following treatment with a novel Syk inhibitor," Clinical Immunology, vol. 124, no. 3, pp. 244-257, 2007.

[69] M. Bajpai, "Fostamatinib, a Syk inhibitor prodrug for the treatment of inflammatory diseases," IDrugs, vol. 12, no. 3, pp. 174-185, 2009.

[70] M. E. Weinblatt, A. Kavanaugh, R. Burgos-Vargas, et al., "Treatment of rheumatoid arthritis with a Syk kinase inhibitor: a twelve-week, randomized, placebo-controlled trial," Arthritis and Rheumatism, vol. 58, no. 11, pp. 33093318, 2008.

[71] C. J. Malemud, "Protein kinases in chondrocyte signaling and osteoarthritis," Clinical Orthopaedics and Related Research, no. 427, supplement, pp. S145-S151, 2004.

[72] G. L. Johnson, H. G. Dohlman, and L. M. Graves, "MAPK kinase kinases (MKKKs) as a target class for small-molecule inhibition to modulate signaling networks and gene expression," Current Opinion in Chemical Biology, vol. 9, no. 3, pp. 325-331, 2005.

[73] C. J. Malemud, "MAP kinases," in OA, Inflammation and Degradation: A Continuum, J. Buckwalter, M. Lotz, and J.F. Stoltz, Eds., vol. 70 of Biomedical and Health Research, pp. 99-117, IOS Press, Amsterdam, The Netherlands, 2007.

[74] I. Breitkreutz, M. S. Raab, S. Vallet, et al., "Targeting MEK1/2 blocks osteoclast differentiation, function and cytokine secretion in multiple myeloma," British Journal of Haematology, vol. 139, no. 1, pp. 55-63, 2007.

[75] H. Hotokezaka, E. Sakai, K. Kanaoka, et al., "U0126 and PD98059, specific inhibitors of MEK, accelerate differentiation of RAW264.7 cells into osteoclast-like cells," The Journal of Biological Chemistry, vol. 277, no. 49, pp. 47366-47372, 2002.

[76] J. M. Waldburger and G. S. Firestein, "Garden of therapeutic delights: new targets in rheumatic diseases," Arthritis Research and Therapy, vol. 11, no. 1, article 206, 2009.

[77] H. B. Kwak, H. M. Sun, H. Ha, J. H. Lee, H. N. Kim, and Z. H. Lee, "AG490, a Jak2-specific inhibitor, induces osteoclast survival by activating the Akt and ERK signaling pathways," Molecules and Cells, vol. 26, no. 5, pp. 436-442, 2008.

[78] L. C. Hofbauer and M. Schoppet, "Clinical implications of the osteoprotegerin/RANKL/RANK system for bone and vascular diseases," Journal of the American Medical Association, vol. 292, no. 4, pp. 490-495, 2004.

[79] A. E. Kearns, S. Khosla, and P. J. Kostenuik, "Receptor activator of nuclear factor $\kappa \mathrm{B}$ ligand and osteoprotegerin regulation of bone remodeling in health and disease," Endocrine Reviews, vol. 29, no. 2, pp. 155-192, 2008.

[80] J. A. McCubrey, M. Milella, A. Tafuri, et al., "Targeting the Raf/MEK/ERK pathway with small-molecule inhibitors," Current Opinion in Investigational Drugs, vol. 9, no. 6, pp. 614-630, 2008.

[81] J. A. McCubrey, L. S. Steelman, S. L. Abrams, et al., "Roles of the RAF/MEK/ERK and PI3K/PTEN/AKT pathways in malignant transformation and drug resistance," Advances in Enzyme Regulation, vol. 46, no. 1, pp. 249-279, 2006.

[82] M. J. Thiel, C. J. Schaefer, M. E. Lesch, et al., "Central role of the MEK/ERK MAP kinase pathway in a mouse model of rheumatoid arthritis: potential proinflammatory mechanisms," Arthritis and Rheumatism, vol. 56, no. 10, pp. 3347-3357, 2007.

[83] M. Ohori, "ERK inhibitors as a potential new therapy for rheumatoid arthritis," Drug News and Perspectives, vol. 21, no. 5, pp. 245-250, 2008.

[84] http://www.pharmalive.com/News/Index.cfm?articleid= 649388.

[85] Y. Nagata, T. Nakasa, Y. Mochizuki, et al., "Induction of apoptosis in the synovium of mice with autoantibodymediated arthritis by the intraarticular injection of doublestranded microRNA-15a," Arthritis and Rheumatism, vol. 60, no. 9, pp. 2677-2683, 2009.

[86] Q. Yao, D. W. Seol, Z. Mi, and P. D. Robbins, "Intraarticular injection of recombinant TRAIL induces synovial apoptosis and reduces inflammation in a rabbit knee model of arthritis," Arthritis Research \& Therapy, vol. 8, no. 1, article R16, 2006.

[87] S.-W. Lee, J.-H. Kim, Y.-B. Park, and S.-K. Lee, "Bortezomib attenuates murine collagen-induced arthritis," Annals of the Rheumatic Diseases, vol. 68, no. 11, pp. 1761-1767, 2009.

[88] L. New, Y. Jiang, M. Zhao, et al., "PRAK, a novel protein kinase regulated by the p38 MAP kinase," EMBO Journal, vol. 17, no. 12, pp. 3372-3384, 1998.

[89] M. Perander, S. M. Keyse, and O.-M. Seternes, "Does MK5 reconcile classical and atypical MAP kinases?" Frontiers in Bioscience, vol. 13, no. 12, pp. 4617-4624, 2008.

[90] E. Åberg, M. Perander, B. Johansen, et al., "Regulation of MAPK-activated protein kinase 5 activity and subcellular localization by the atypical MAPK ERK4/MAPK4," The Journal of Biological Chemistry, vol. 281, no. 46, pp. 3549935510, 2006.

[91] M. Gaestel, "Specificity of signaling from MAPKs to MAPKAPKs: kinases' tango nuevo," Frontiers in Bioscience, vol. 13, pp. 6050-6059, 2008.

[92] S. Kostenko, M. Johannessen, and U. Moens, "PKA-induced F-actin rearrangement requires phosphorylation of $\mathrm{Hsp} 27$ by the MAPKAP kinase MK5," Cellular Signalling, vol. 21, no. 5, pp. 712-718, 2009.

[93] K. L. Wood, H. L. Twigg III, and A. I. Doseff, "Dysregulation of CD8+ lymphocyte apoptosis, chronic disease, and immune regulation," Frontiers in Bioscience, vol. 14, pp. 3771-3781, 2009.

[94] M. F. Roelofs, W. C. Boelens, L. A. B. Joosten, et al., "Identification of small heat shock protein B8 (HSP22) as a novel TLR4 ligand and potential involvement in the pathogenesis of rheumatoid arthritis," Journal of Immunology, vol. 176, no. 11, pp. 7021-7027, 2006.

[95] E. Åberg, K. M. Torgersen, B. Johansen, S. M. Keyse, M. Perander, and O.-M. Seternes, "Docking of PRAK/MK5 to the atypical MAPKs ERK3 and ERK4 defines a novel MAPK interaction motif," The Journal of Biological Chemistry, vol. 284, no. 29, pp. 19392-19401, 2009.

[96] M. Yoshida, M. Niwa, A. Ishisaki, et al., "Methotrexate enhances prostaglandin $\mathrm{D}_{2}$-stimulated heat shock protein 27 induction in osteoblasts," Prostaglandins Leukotrienes and Essential Fatty Acids, vol. 71, no. 6, pp. 351-362, 2004.

[97] S. Medicherla, J. Y. Ma, R. Mangadu, et al., "A selective p38 $\alpha$ mitogen-activated protein kinase inhibitor reverses cartilage and bone destruction in mice with collagen-induced arthritis," Journal of Pharmacology and Experimental Therapeutics, vol. 318, no. 1, pp. 132-141, 2006.

[98] N. Gerits, A. Shiryaev, S. Kostenko, et al., "The transcriptional regulation and cell-specific expression of the 
MAPK-activated protein kinase MK5," Cellular and Molecular Biology Letters, vol. 14, no. 4, pp. 548-574, 2009.

[99] P. Sun, N. Yoshizuka, L. New, et al., "PRAK Is essential for rasinduced senescence and tumor suppression," Cell, vol. 128, no. 2, pp. 295-308, 2007.

[100] W. H. Faour, Q. He, A. Mancini, D. Jovanovic, J. Antoniou, and J. A. Di Battista, "Prostaglandin $\mathrm{E}_{2}$ stimulates p53 transactivational activity through specific serine 15 phosphorylation in human synovial fibroblasts: role in suppression of c/EBP/NF- $\kappa \mathrm{B}$-mediated MEKK1-induced MMP-1 expression," The Journal of Biological Chemistry, vol. 281, no. 29, pp. 19849-19860, 2006.

[101] E. Šimelyte, S. Rosengren, D. L. Boyle, M. Corr, D. R. Green, and G. S. Firestein, "Regulation of arthritis by p53: critical role of adaptive immunity," Arthritis and Rheumatism, vol. 52, no. 6, pp. 1876-1884, 2005.

[102] http://nmcc-vikas.gov.in/AhmedabadPharma/Galapagos .html.

[103] M. Fabbri, C. M. Croce, and G. A. Calin, "MicroRNAs," Cancer Journal, vol. 14, no. 1, pp. 1-6, 2008.

[104] H. F. Lodish, B. Zhou, G. Liu, and C.-Z. Chen, "Micromanagement of the immune system by microRNAs," Nature Reviews Immunology, vol. 8, no. 2, pp. 120-130, 2008.

[105] B. P. Lewis, C. B. Burge, and D. P. Bartel, "Conserved seed pairing, often flanked by adenosines, indicates that thousands of human genes are microRNA targets," Cell, vol. 120, no. 1, pp. 15-20, 2005.

[106] E. Karouzakis, R. E. Gay, S. Gay, and M. Neidhart, "Epigenetic control in rheumatoid arthritis synovial fibroblasts," Nature Reviews Rheumatology, vol. 5, no. 5, pp. 266-272, 2009.

[107] K. D. Taganov, M. P. Boldin, K.-J. Chang, and D. Baltimore, "NF- $\kappa$ B-dependent induction of microRNA miR-146, an inhibitor targeted to signaling proteins of innate immune responses," Proceedings of the National Academy of Sciences of the United States of America, vol. 103, no. 33, pp. 1248112486, 2006

[108] R. M. O’Connell, K. D. Taganov, M. P. Boldin, G. Cheng, and D. Baltimore, "MicroRNA-155 is induced during the macrophage inflammatory response," Proceedings of the National Academy of Sciences of the United States of America, vol. 104, no. 5, pp. 1604-1609, 2007.

[109] D. P. Bartel, "MicroRNAs: genomics, biogenesis, mechanism, and function," Cell, vol. 116, no. 2, pp. 281-297, 2004.

[110] T. Nakasa, S. Miyaki, A. Okubo, et al., "Expression of microRNA-146 in rheumatoid arthritis synovial tissue," Arthritis and Rheumatism, vol. 58, no. 5, pp. 1284-1292, 2008.

[111] J. Stanczyk, D. M. L. Pedrioli, F. Brentano, et al., "Altered expression of microRNA in synovial fibroblasts and synovial tissue in rheumatoid arthritis," Arthritis and Rheumatism, vol. 58, no. 4, pp. 1001-1009, 2008.

[112] K. M. Pauley, M. Satoh, A. L. Chan, M. R. Bubb, W. H. Reeves, and E. K. L. Chan, "Upregulated miR-146a expression in peripheral blood mononuclear cells from rheumatoid arthritis patients," Arthritis Research and Therapy, vol. 10, no. 4, article R101, 2008.

[113] M. K. Ameriks and J. D. Venable, "Small molecule inhibitors of phosphoinositide 3-kinase (PI3K) $\delta$ and $\gamma$," Current Topics in Medicinal Chemistry, vol. 9, no. 8, pp. 738-753, 2009.

[114] C. Rommel, M. Camps, and H. Ji, "PI3K $\delta$ and PI3K $\gamma$ : partners in crime in inflammation in rheumatoid arthritis and beyond?" Nature Reviews Immunology, vol. 7, no. 3, pp. 191-201, 2007.
[115] E. H. Kang, D. J. Kim, E. Y. Lee, Y. J. Lee, E. B. Lee, and Y. W. Song, "Downregulation of heat shock protein 70 protects rheumatoid arthritis fibroblast-like synoviocytes from nitric oxide-induced apoptosis," Arthritis Research \& Therapy, vol. 11, no. 4, article R130, 2009.

[116] Y. Lin, C.-C. Su, J.-Y. Huang, et al., "Aberrant integrin activation induces p38 MAPK phosphorylation resulting in suppressed Fas-mediated apoptosis in T cells: implications for rheumatoid arthritis," Molecular Immunology, vol. 46, no. 16, pp. 3328-3335, 2009.

[117] A. K. Mankan, M. W. Lawless, S. G. Gray, D. Kelleher, and R. McManus, "NF- $\kappa$ B regulation: the nuclear response," Journal of Cellular and Molecular Medicine, vol. 13, no. 4, pp. 631643, 2009.

[118] S. Palmer and Y. H. Chen, "Bcl-3, a multifaceted modulator of NF- $\kappa \mathrm{B}$-mediated gene transcription," Immunologic Research, vol. 42, no. 1-3, pp. 210-218, 2008.

[119] U. Meusch, M. Rossol, C. Baerwald, S. Hauschildt, and U. Wagner, "Outside-to-inside signaling through transmembrane tumor necrosis factor reverses pathologic interleukin$1 \beta$ production and deficient apoptosis of rheumatoid arthritis monocytes," Arthritis and Rheumatism, vol. 60, no. 9, pp. 2612-2621, 2009.

[120] D. C. Phillips, H. I. Dias, G. D. Kitas, and H. R. Griffiths, "Aberrant reactive oxygen and nitrogen species generation in rheumatoid arthritis (RA): causes and consequences for immune function, cell survival and therapeutic intervention," Antioxid Redox Signal. In press.

[121] J. Hutcheson and H. Perlman, "BH3-only proteins in rheumatoid arthritis: potential targets for therapeutic intervention," Oncogene, vol. 27, supplement 1, pp. S168-S175, 2008.

[122] C. Falschlehner, T. M. Ganten, R. Koschny, U. Schaefer, and H. Walczak, "TRAIL and other TRAIL receptor agonists as novel cancer therapeutics," Advances in Experimental Medicine and Biology, vol. 647, pp. 195-206, 2009.

[123] J. Morel, R. Audo, M. Hahne, and B. Combe, "Tumor necrosis factor-related apoptosis-inducing ligand (TRAIL) induces rheumatoid arthritis synovial fibroblast proliferation through mitogen-activated protein kinases and phosphatidylinositol 3-kinase/Akt," The Journal of Biological Chemistry, vol. 280, no. 16, pp. 15709-15718, 2005.

[124] A. Jüngel, V. Baresova, C. Ospelt, et al., "Trichostatin A sensitises rheumatoid arthritis synovial fibroblasts for TRAIL-induced apoptosis," Annals of the Rheumatic Diseases, vol. 65, no. 7, pp. 910-912, 2006.

[125] M. Tamai, A. Kawakami, F. Tanaka, et al., "Significant inhibition of TRAIL-mediated fibroblast-like synovial cell apoptosis by IFN- $\gamma$ through JAK/STAT pathway by translational regulation," Journal of Laboratory and Clinical Medicine, vol. 147, no. 4, pp. 182-190, 2006.

[126] M. Bonmort, E. Ullrich, G. Mignot, B. Jacobs, N. Chaput, and L. Zitvogel, "Interferon- $\gamma$ is produced by another player of innate immune responses: the interferon-producing killer dendritic cell (IKDC)," Biochimie, vol. 89, no. 6-7, pp. 872877, 2007.

[127] S. Häcker, A. Dittrich, A. Mohr, et al., "Histone deacetylase inhibitors cooperate with IFN- $\gamma$ to restore caspase- 8 expression and overcome TRAIL resistance in cancers with silencing of caspase-8," Oncogene, vol. 28, no. 35, pp. 3097-3110, 2009.

[128] R. Audo, B. Combe, B. Coulet, J. Morel, and M. Hahne, "The pleiotropic effect of TRAIL on tumor-like synovial fibroblasts from rheumatoid arthritis patients is mediated by caspases," 
Cell Death and Differentiation, vol. 16, no. 9, pp. 1227-1237, 2009.

[129] N. Pundt, M. A. Peters, C. Wunrau, et al., "Susceptibility of rheumatoid arthritis synovial fibroblasts to FasL- and TRAIL-induced apoptosis is cell cycle-dependent," Arthritis Research and Therapy, vol. 11, no. 1, article R16, 2009.

[130] E. Terzioglu, A. Bisgin, A. D. Sanlioglu, et al., "Concurrent gene therapy strategies effectively destroy synoviocytes of patients with rheumatoid arthritis," Rheumatology, vol. 46, no. 5, pp. 783-789, 2007.

[131] X. Liu, P. Yue, F. R. Khuri, and S.-Y. Sun, "Decoy receptor 2 (DcR2) is a p53 target gene and regulates chemosensitivity," Cancer Research, vol. 65, no. 20, pp. 9169-9175, 2005.

[132] C. J. Malemud, "Gene therapy for arthritis: defining novel gene targets," Gene Therapy and Molecular Biology, vol. 11, no. 1, pp. 27-36, 2007.

[133] J. Adams, "The proteasome: a suitable antineoplastic target," Nature Reviews Cancer, vol. 4, no. 5, pp. 349-360, 2004.

[134] J. M. Peters, W. W. Franke, and J. A. Kleinschmidt, "Distinct $19 S$ and 20 S subcomplexes of the 26 S proteasome and their distribution in the nucleus and cytoplasm," The Journal of Biological Chemistry, vol. 269, no. 10, pp. 7709-7718, 1994.

[135] J. Wang and M. A. Maldonado, "The ubiquitin-proteasome system and its role in inflammatory and autoimmune diseases," Cellular \& Molecular Immunology, vol. 3, no. 4, pp. 255-261, 2006.

[136] P. J. Elliott, T. M. Zollner, and W.-H. Boehncke, "Proteasome inhibition: a new anti-inflammatory strategy," Journal of Molecular Medicine, vol. 81, no. 4, pp. 235-245, 2003.

[137] M. K. Bennett and C. J. Kirk, "Development of proteasome inhibitors in oncology and autoimmune diseases," Current Opinion in Drug Discovery and Development, vol. 11, no. 5, pp. 616-625, 2008.

[138] B. S. Moore, A. S. Eustáquio, and R. P. McGlinchey, "Advances in and applications of proteasome inhibitors," Current Opinion in Chemical Biology, vol. 12, no. 4, pp. 434440, 2008.

[139] J. Brun, "Proteasome inhibition as a novel therapy in treating rheumatoid arthritis," Medical Hypotheses, vol. 71, no. 1, pp. 65-72, 2008.

[140] U. G. Bhat, M. Halasi, and A. L. Gartel, "FoxM1 is a general target for proteasome inhibitors," PLoS ONE, vol. 4, no. 8, article e6593, 2009.

[141] C. Berges, H. Haberstock, D. Fuchs, et al., "Proteasome inhibition activates the mitochondrial pathway of apoptosis in human CD4+ T cells," Journal of Cellular Biochemistry, vol. 108, no. 4, pp. 935-946, 2009.

[142] J. W. van der Heijden, R. Oerlemans, W. F. Lems, R. J. Scheper, B. A. C. Dijkmans, and G. Jansen, "The proteasome inhibitor bortezomib inhibits the release of $\mathrm{NF} \kappa \mathrm{B}$-inducible cytokines and induces apoptosis of activated $\mathrm{T}$ cells from rheumatoid arthritis patients," Clinical and Experimental Rheumatology, vol. 27, no. 1, pp. 92-98, 2009.

[143] J. A. Roman-Blas and S. A. Jimenez, "Targeting NF- $\kappa$ B: a promising molecular therapy in inflammatory arthritis," International Reviews of Immunology, vol. 27, no. 5, pp. 351374, 2008.

[144] L. Rifas and M. N. Weitzmann, "A novel T cell cytokine, secreted osteoclastogenic factor of activated $\mathrm{T}$ cells, induces osteoclast formation in a RANKL-independent manner," Arthritis and Rheumatism, vol. 60, no. 11, pp. 3324-3335, 2009.
[145] H. B. Kwak, M. S. Lee, H. S. Kim, et al., "Proteasome inhibitors induce osteoclast survival by activating the Akt pathway," Biochemical and Biophysical Research Communications, vol. 377, no. 1, pp. 1-6, 2008. 


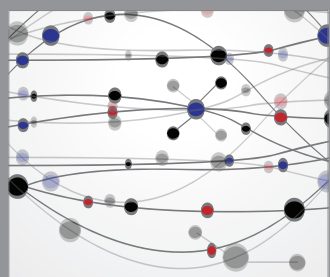

The Scientific World Journal
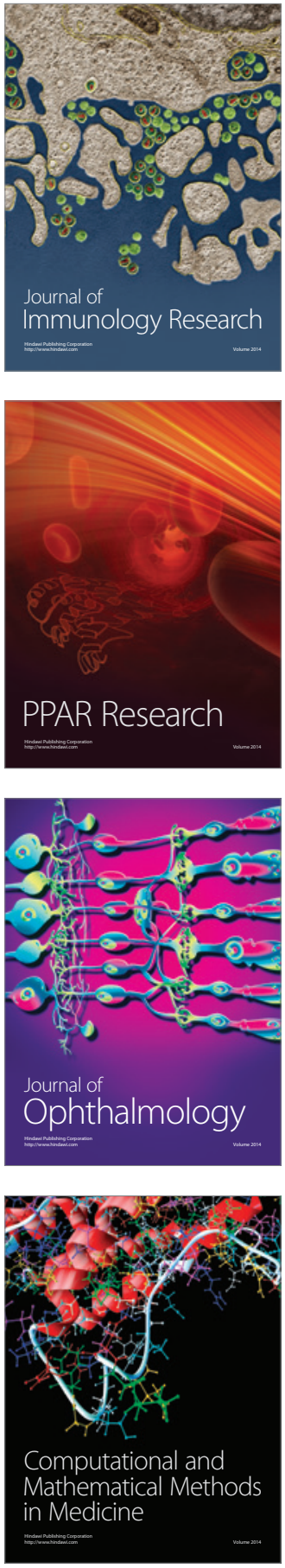

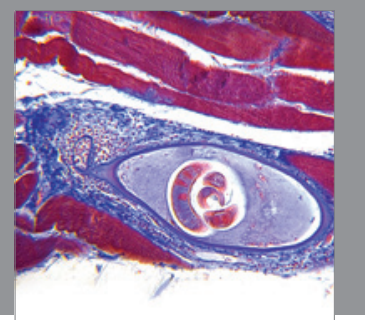

Gastroenterology

Research and Practice
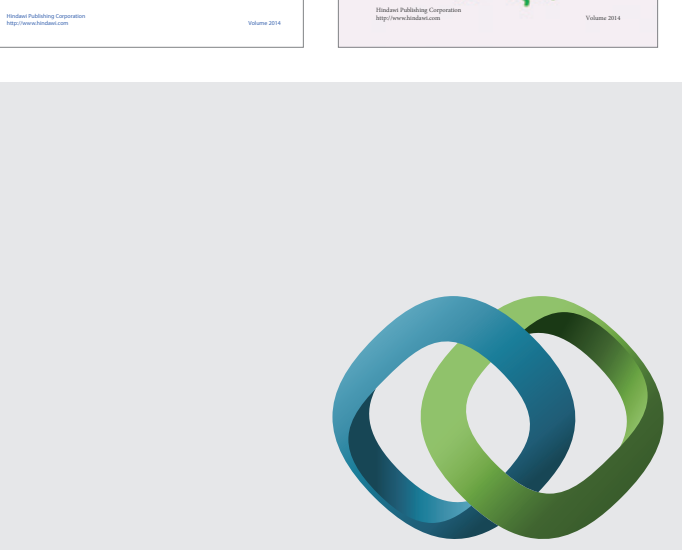

\section{Hindawi}

Submit your manuscripts at

http://www.hindawi.com
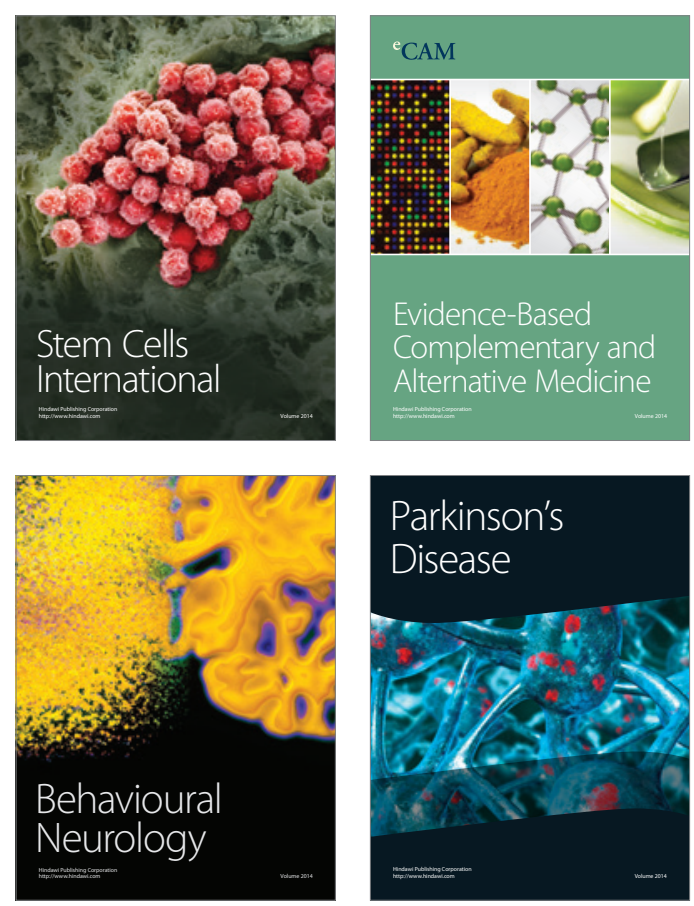

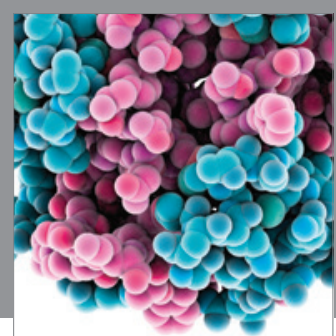

Journal of
Diabetes Research

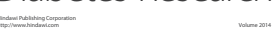

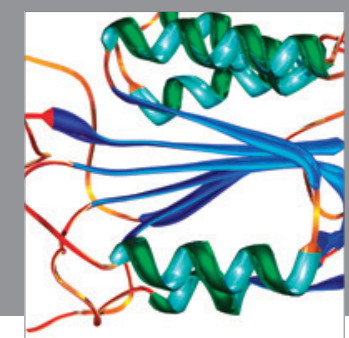

Disease Markers
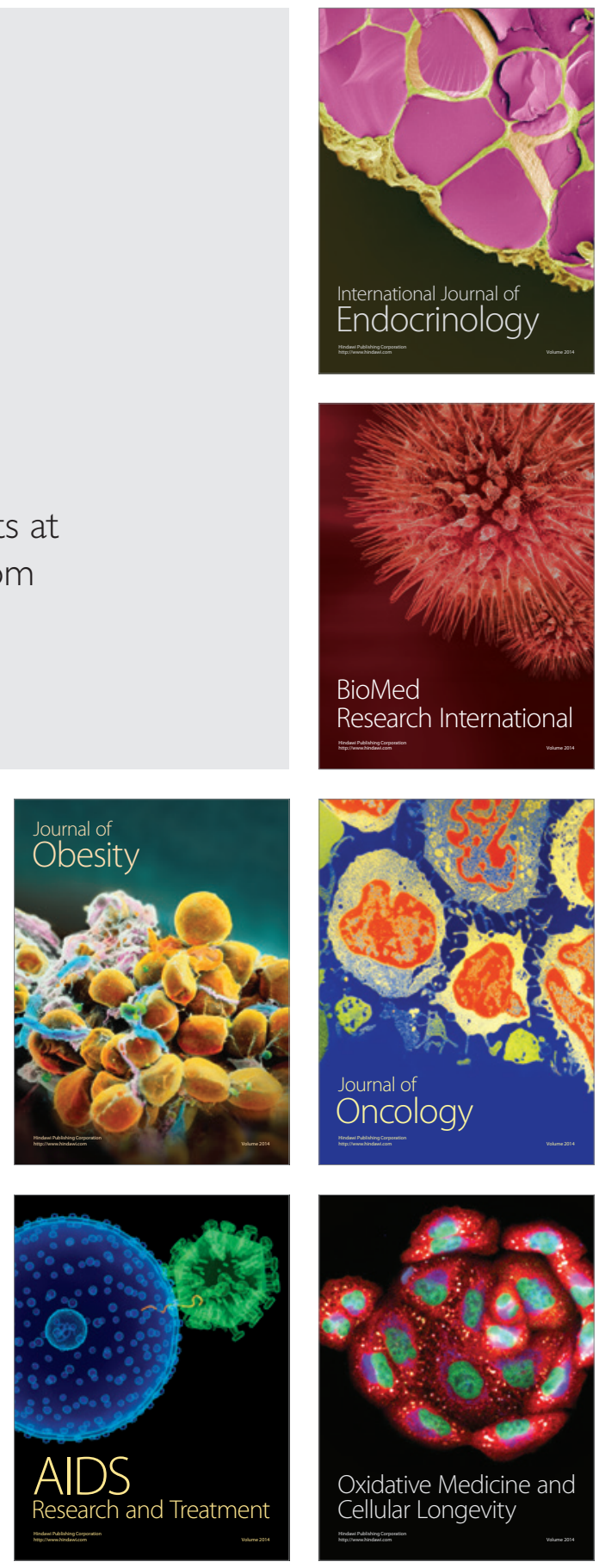